\title{
MTR TEST EQUIPMENT
}

by

W. F. Bell

Pile Engineering Division

January 1956

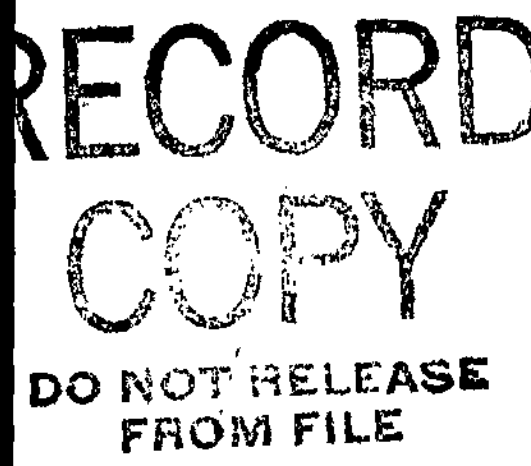

E. I. du Pont de Nemours \& Co.

Explosives Department - Atomic Energy Division

Tochnical Division - Savannah River Laboratory 


\title{
DECLASSIFIED
}

\author{
$D P-114$
}

REACTORS - RESEARCH AND TESTING

MTR TEST EQUIPMENT

by

W. F. BelI

Pile Engineering Division

January 1956

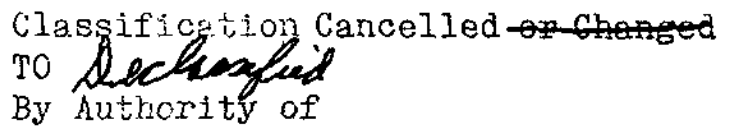

$T(D-1 / 4)$ vol. 13 ne 7 t/s/s? None Title Date

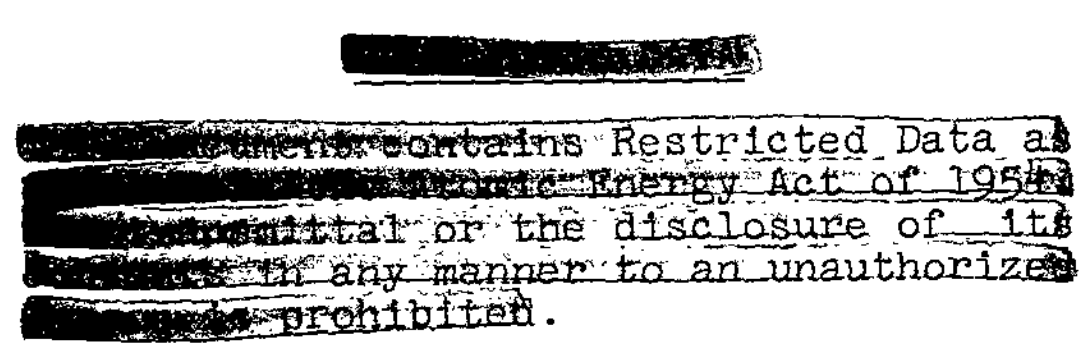
HSA $8 / C / T_{y}$ hL $3 / 20 / 50^{\circ}$

E. I. du Pont de Nemours \& Co.

Explosives Department - Atomic Energy Division Technical Division - Savannah River Laboratory

Printed for

The United States Atomic Energy Commission Contract AT(07-2)-1 


\section{ABSTRACT}

Sample holders and monitoring equipment were designed and fabricated for use in the irradiation of experimental shapes of fuel and target materials in the beryllium reflector of the Materials Testing Reactor. The samples were held in aluminum cases designed to replace certain beryllium blocks of the reflector. Sample holders of alternate designs were made to permit irradiation of samples in the reflector at locations where the shape or position of the reflector blocks would not permit the use of the original design.

External Distribution according to M-3679 (17th Ed.) 


\section{TABLE OF CONTENTS}

\section{Page}

INTRODUCTION

SUMMARY

DISCUSSION

Purpose

Equipment for Flat Plates -

Equipment for Tubes

Equipment for Solid Cylinders

BIBLIOGRAPHY

APPENDIX

Detail Drawings of Equipment 


\section{LIST OF FIGURES}

FIGURE

Page

I Bundle of Uranium Plates

2 Partially Disassembled Plate Bundle

3 Sample Holder for Plates

4 Top Fitting Pin with Captive Screw

5 Quick-Connect Pressure Coupling

6 Instrument Assembly for Plate Sample Holder

7 Arrangement of Instrument Probes for Monitoring of Effluent from Plate Elements

8 Socket Arrangement for Monitoring of Effluent from Plate Elements

9 Sample Holder for Tubes

10 Partially Disassembled Sample Holder for Tubes

11 Sample Holder for Tubes with Small Inside Diameter

12 Sample Holder and Instrument Assembly for Cylinders 


\section{MTR TEST EQUIPNENT}

INTRODUCTION

Experimental fuel and target elements of various shapes were irradiated in the high neutron fluxes of the MTR to evaluate their dimensional stability and the adequacy of the methods of fabrication. Since the smallest samples that could be fabricated for test purposes were too large for handling in the test holes of the reactor, the irradiations were made in the beryllium reflector. This report describes the equipment used for the irradiations.

\section{SUMMARY}

Equipment was designed and fabricated for irradiating samples of fissionable material in the shape of plates, tubes, and cylinders in the MTR. These samples were held in aluminum cases designed to replace certain beryllium blocks of the reflector. The behavior of the fuel was monitored by measuring the flow and temperature of the coolant and by continuously measuring the radioactivity of a sample stream of coolant. Sample holders of alternate designs were made to permit irradiation of samples in the reflector at locations where the shape or position of the reflector blocks would not permit the use of the original design.

\section{DISCUSSION}

PURPOSE

The Materials Testing Reactor was designed for experimental irradiation of different materials, experimental fuel elements, and instruments in a high neutron flux. It has facilities for frequent inspection of the samples to follow the trend of physical changes during irradition. $(1)(2)(3)$

The equipment discussed in this report was designed for the irradiation of various clad uranium shapes in the beryllium reflector of the reactor. The reflector consists of closely fitted beryllium bars, the majority of which are "A" pieces, 3 inches square by $37-1 / 2$ inches long. Each piece is attached to a "bottom snout" which fits into the aluminum casting or "grid" that supports the fuel assemblies and reflector pieces. The reflector is cooled by water that flows down vertically between the beryllium blocks. The pressure drop through an "A" position is about $40 \mathrm{psi}$. The beryllium blocks and any assemblies that replace them must be discharged from the reactor to the canal by passing through a discharge tube that has an inner diameter of $4-3 / 4$ inches. 
In-pile monitoring of the test specimens requires measurements of the temperature rise of the cooling water, of the flow through the sample holder, and of the activity of the effluent to detect fission products. To measure the neutron flux along the length of the specimen, cobalt-aluminum wires are inserted into each sample holder.

\section{EQUIPMENT FOR FLAT PLATES}

Five flat plates of uranium, approximately $1 / 4$ inch thick, 3-1/4 inches wide, and 27 inches 1ong, are shown assembled into a bundle in Figure 1 . In one test, three sample plates were separated by two solid aluminum plates that had ribs. The purpose of the ribs was to maintain a minimum cooling water channel if the test samples warped during irradiation. The partially disassembled plate bundle is shown in Figure 2. The plates are separated at the top by streamlined stainless steel washers, called boat-tails, and are separated at the bottom by aluminum buttons. The plates are clamped firmly together by the upper bolt which passes through each boat-tail. The heads of the bolt support the bundle in the sample holder during the irradiation test. The lower bolt, with unthreaded extensions on each end, screws into the slot at the bottom of the center plate. The bolt extensions fit loosely into slots in the other plates to prevent them from fanning out when the bundle is handled remotely during inspection. The slots have sufficient clearance to accommodate unequal changes in the length of the plates, during irradiation.

Since the plates are wider than an "A" piece, the sample holder assembly was required to be larger than an "A" piece. To accommodate the sample holder, an instrument assembly that is smaller than an "A" piece was designed to occupy an adjacent "A" position. The design permits the sample holder assembly to be removed without disturbing the instrument assembly.

The sample holder assembly, in Figure 3, consists of a top fitting, a body, and a snout. The equipment is handled in the reactor or canal by the standard tool used at the MTR to grip the stainless steel lifting pins in the top of the reflector blocks.

The top fitting is made in two parts to provide a seat for an orifice plate. The orifices can be changed remotely by removing four socket-head cap screws. The top fitting assembly is connected to the main body by stainless steel pins that extend through holes in the fitting and the sides of the body. The pins are grooved so that they can be held in position after assembly by captive screws of stainless steel, as shown in Figure 4. 
The body is rectangular in cross section with outside dimensions of 3.8 inches by 3 inches. The four sides are bolted together by stainless steel screws of the socket-head type to permit remote disassembly of the sample holder if distortion of the fuel prevents it from being withdrawn through the top opening. The inside dimensions of the sample holder are 3.350 inches by 1.750 inches providing a clearance between the bundle and holder of 0.050 inch on the edge and 0.070 inch on the flat surface. Ribs machined on two of the inside surfaces of the sampie holder provide a minimum coolant channel if the plates warp during irradiation. Slots that are machined in the same two surfaces of the holder contain the heads of the upper bolt to support the bundle. The cobalt-aluminum wires for flux monitoring are located along each joint at the corners of the body in 1/16-inch square slots. The wires are removed by disassembling the main body.

The snout, similar to the bottom fitting of a beryliium "A" piece, has a hole $1-3 / 4$ inches in diameter through the center. It is attached to the sample holder by screws that permit remote disassembly. Stainless steel inserts are provided for all bolts and screws used for the assembiy of the sample holder. These inserts prevent galling of the threads by repeated disassembly of the parts.

Cooling water is admitted to the sample holder through the four large openings at the base of the lifting pin. Water then passes through the orifice, across the sample bundle, and is discharged from the snout into the lower plenum of the reactor.

Flow is measured by means of the pressure drop across the orifice. The upstream pressure tap is suspended in the upper plenum above the grid of the reactor. The downstream pressure tap is connected to a differential pressure transmitter by a quick-connect coupling that can be operated remotely.

The coupling, illustrated in Figure 5, has no gaskets, but depends on a clearance of 0.0015 inch between mating parts to minimize leakage at operating pressures. The quick-connect feature allows the pressure line to be easily attached to or removed from the sample holder. A long-handled tool is provided to operate this connector in the reactor.

The instrument assembly, consisting of the body, snout, and instrument probes, is shown in Figure 6 . The body is solid aluminum with a cross section 2.2 inches by 3 inches. Slots milled down the side of the body contain two probes, 1/4 inch in diameter, that extend into the snout. The U-shaped lower end of each probe can be rotated through $180^{\circ}$ within the snout. The probes are spring-loaded for positive seating of the $U$ in the appropriate notch. In Figure 7 the probes are in the retracted position to allow the snout to enter the lower grid of the reactor. After the instrument assembly is inserted, the probes are rotated to extend into the effluent stream from the adjacent snout of the sample holder. This instrument probe arrangement can be used only when two adjacent "A" positions are selected for the sample holder and instrument assembly. 
At some positions in the reactor a stiffening web below the lower grid casting separates the effluent from two "A "positions. Because of space limitations in the reactor, it is occasionally necessary to use such positions for an irradiation. The socket arrangement, Flgure 8, was designed to monitor the effluent in such a position. The thickness of the instrument assembly was reduced so that its snout was offset sufficiently to support the lower end of a sample holder that had no snout. A short tapered plug was attached to the bottom of the body to replace the snout. The tapered socket in the offset of the instrument snout accepts the plug thereby discharging the effluent from the sample holder through the instrument snout past fixed instrument probes. A fill-in snout is provided to block the hole in the lower grid below the sample holder.

Due to the demand for "A" test positions, two adjacent ones are not always avallable for a single experiment. For this reason the socket arrangement was also adapted for use in adjoining "A" and "B" reflector positions. The triangular shaped " $B$ " position is not designed for experiments that require cooling flow since no effluent hole was provided in the lower grid casting. In this case, the socket-type instrument box occupies a portion of the "A" position. The sample holder fills the remainder of the "A" position and extends into the " $B$ " position. Aluminum filler pieces occupy the remaining space of the "B" position.

The sample holder is discharged from the reactor by releasing the remote coupling and lifting the holder from the test position into the discharge tube. It is lowered through the discharge tube into the disassembly canal below the reactor.

The sample holder is disassembled and the elements are inspected under ten feet of water in the canal. Only the simplest of long-handled tools are required for easy disassembly. Socket screw wrenches and a Phillips screw driver will remove all screw fasteners. Hooks handle the less bulky parts while snares are provided for the heavier assemblies. Small grippers are used to assemble the upper plate bolt into the bundle and to recover small parts dropped during disassembly.

The sample holder is disassembled in the following steps:

1. The holder is supported in the vertical position in a steel frame.

2. The captive locking screws in the top fitting are loosened with a socket screw wrench.

3. The top fitting pins are removed with a claw-shaped tool and placed in holes provided in the steel frame. hook.

4. The top fitting is lifted from the sample holder with a

5. The bundle of plates 1s withdrawn from the sample holder with a hook which fits under the boat-tail washers that separate the plates.

6. The bundle is grasped by snares and placed in a horizontal position on the inspection table. 
7. The upper bolt is removed; each plate can then be handled separately .

An inspection table in the canal will accommodate individual irradiated plates in positions for making measurements. Support blocks hold the plate on edge over a surface of alternate black and white lines $1 / 8$ inch wide. With these lines parallel to the axis of the plate, a visual estimate of the amount of bow is made. Snap gauges on long handles are used to measure thickness, length, and width of the plate. Photographs are then taken of each surface of the plate by using a camera equipped with a telephoto lens. After inspection, the plates may be reassembled into the sample holder and returned through the discharge tube to the reactor for further irradiation.

EQUIPMENT FOR TUBES

For the irradiation of tubular elements, the sample holder and instrument assembly are designed to fit a single "A" position. Typical tubes that were irradiated were 29 inches long about 2.5 inches in diameter, with wall thicknesses of 0.140 to 0.275 inch.

As shown in Figure 9, the sample holder is an assembly of top fitting, body, and snout. The instrument assembly, a separately removable part of the sample holder, extends through the center of the sample tube. The two lifting pins allow remote handling of either the instrument assembly or the sample holder in the reactor.

The top fitting has an orifice seat and downstream pressure tap with a quick-connect coupling. The fitting is attached to the body by two captive socket-head cap screws. The partially disassembled sample holder in Figure 10 shows the bayonet lock provided on the extension barrel of the top fitting for holding the instrument assembly in position. Circumferential slots at the base of the barrel admit cooling water to the sample tube.

The body is a 3-inch square aluminum bar bored to 2.720-inch diameter. It is split diagonally and bolted together to permit disassembly in case the tube becomes distorted during irradiation. Four longitudinal ribs spaced around the inner bore maintain passages around the tube for coolant if distortion should occur. A radial clearance of 0.030 inch is provided between the ribs and most of the length of the tube. To reduce vibration, the rib height was increased to make the clearance 0.005 inch at the lower end of the ribs. The tube rests on four buttons protruding from the inner bore of the holder with a fifth button engaging a slot in the tube for indexing. About 1-1/2 inches is allowed for longitudinal growth of the sample. Slots are provided along the joints of the body for cobalt-aluminum wires to measure the neutron flux.

The snout design is the same as that used on the plate sample holder. 
The instrument assembly, extending through the center of the tube, is an aluminum pipe containing the thermocouple and effluent sampling probes. The outer diameter defines the width of the cooling water annulus inside the fuel tube. Short longitudinal ribs at the ends and center of the instrument assembly space it concentrically with the tube. Radial clearance between the ribs and the inside of the tube is 0.030 inch except at the top where it is 0.003 inch to reduce vibration. Two instrument probes extend from the bottom of the instrument assembly with their U-shaped ends inside the snout about 5 inches below the bottom of the sample tube. Flexible stainless steel Iines, connected to the probes at the top of the instrument assembly, allow removal of the assembly from the sample holder without disconnecting the probes from their recorders.

- Disassembly of the sample holder is completed in the following steps:

1. The quick-connect fitting is released while the assembly is in the reactor.

holder.

2. The instrument assembly is removed from the sample

3. The sample holder is discharged to the canal.

4. The sample holder is supported vertically in a steel

frame in the canal.

5. The bolts in the top fitting are released with a socket screw wrench.

6. The top fitting is removed with a hook.

7. The sample tube is withdrawn with a hook that is inserted into one of the holes at the top of the tube.

The inspection table for tubes will accommodate diameters from 1.8 inches to 2.5 inches. For inspection, a tube is placed in $\mathrm{V}$-blocks with one end butted against a reference block. A dial indicator, fixed to the table, bears against the other end of the tube to indicate the length. Bow and diameter are measured by a dial indicator and a snap gauge on long handles.

A modification of the sample holder for tubes is shown in Figure 11. It will contain a tube with inside dimension too small to include both the instrument probes in the inner housing assembly. This sample tube is about 2 inches outside diameter with a wall thickness of $0.43 \mathrm{inch}$. The instrument assembly extending down the center of the tube contains only the thermocouple probe. The effluent sampling tube is contained in a circular slot in a corner of the diagonal joint of the sample holder. A quick-connect coupling permits remote connection of this probe with the fission break indicator outside the reactor tank.

EQUIPMENT FOR SOLID CYLINDERS

Standard "AB" beryllium pieces are available at the MTR for irradiating cylinders of about 1 inch diameter in a single "A" position. Interest in cylinders about $1-7 / 8$ inches diameter required another 
design to contain a sample of this size.

The previously described socket arrangement was modifled to accommodate both sample holder and instrument assembly in one " $A$ " position. This arrangement, shown in Figure 12, provides an instrument assembly with a thin body, 0.700 inch by. 3 inches, and the offset snout containing the two standard instrument probes. The body of the sample holder, 2.250 inches by 3 inches in cross section with a 2 -inch diameter bore, has a tapered bottom plug to seat in the tapered socket of the offset snout. Ribs inside the bore maintain an annulus for coolant flow during irradiation. The top fitting is similar to that for the plate sample holder with lifting pin, quick-connect pressure fitting, and orifice plate seat.

Inspection of the sample cylinders in the canal is similar to that previously described for plates and tubes.

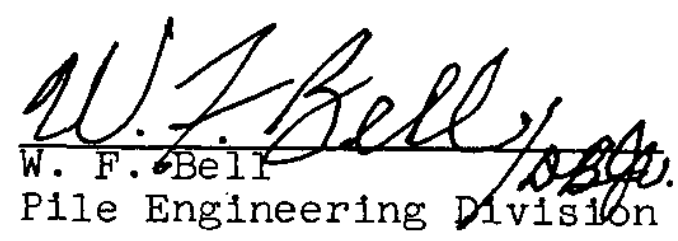

\section{BIBLIOGRAPHY}

1. Leyse, C. F. Phillips Petroleum Co., IDO-16048, June 5, 1953 (classified report).

2. Buck, J. H. and Leyse, C. F. Argonne National Lab. and Oak Ridge National Lab., ORNL-963, May 7, 1951 (classified report).

3. Pennington, W. H. Phillips Petroleum Co., IDO-16178, June 17, 1954 (classified report). 


\section{FIGURE I}

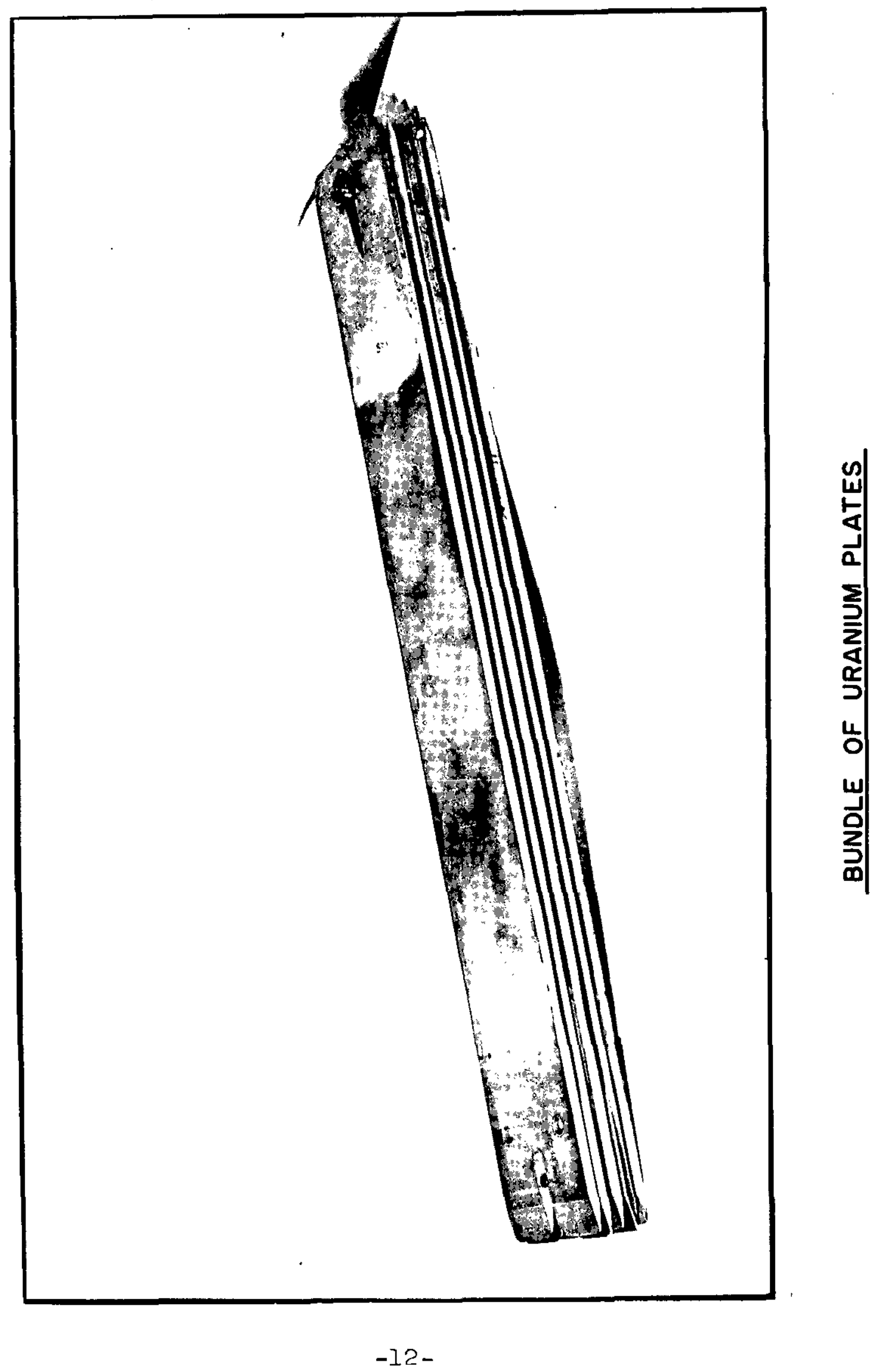




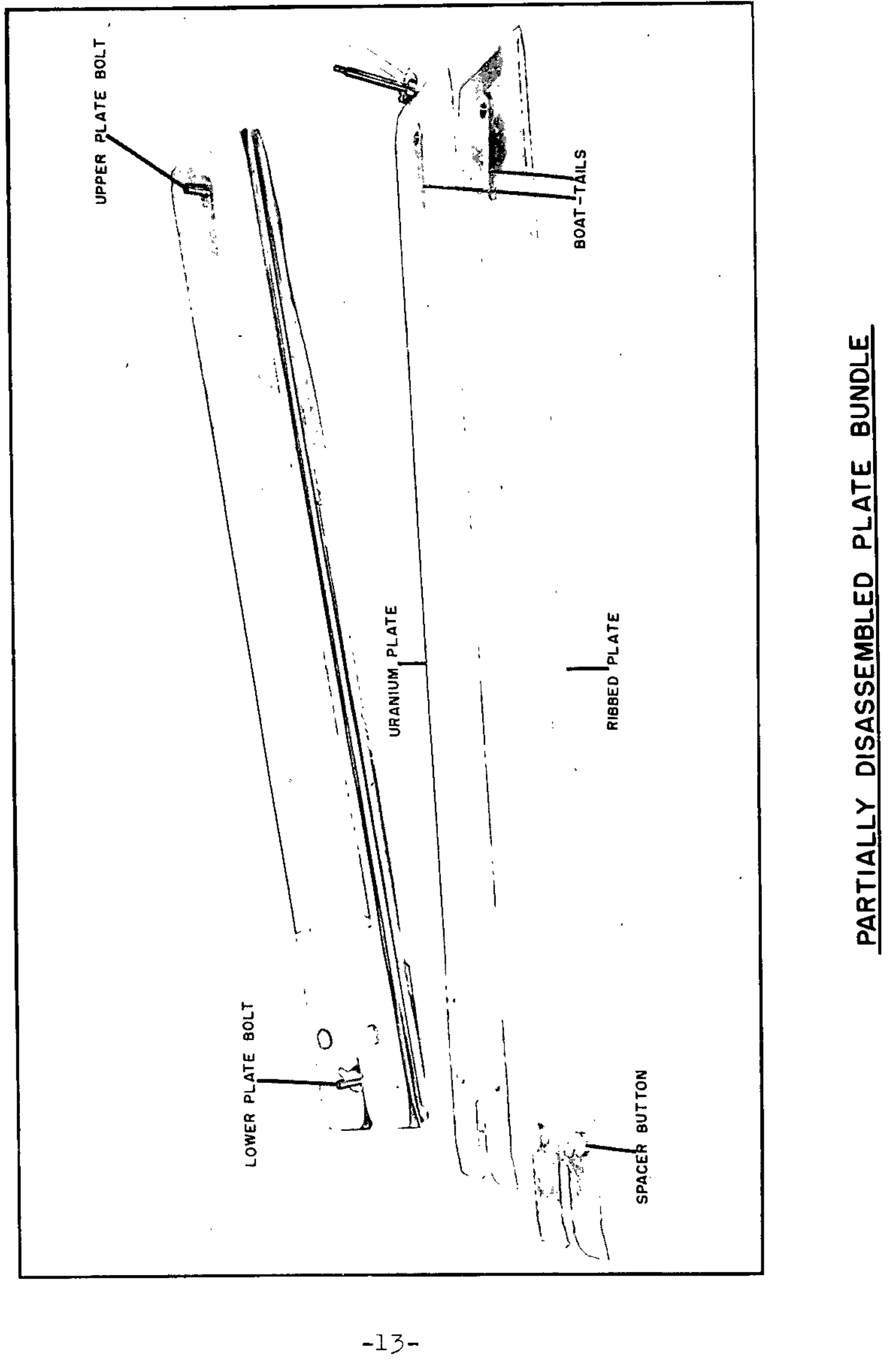




\section{FIGURE 3}

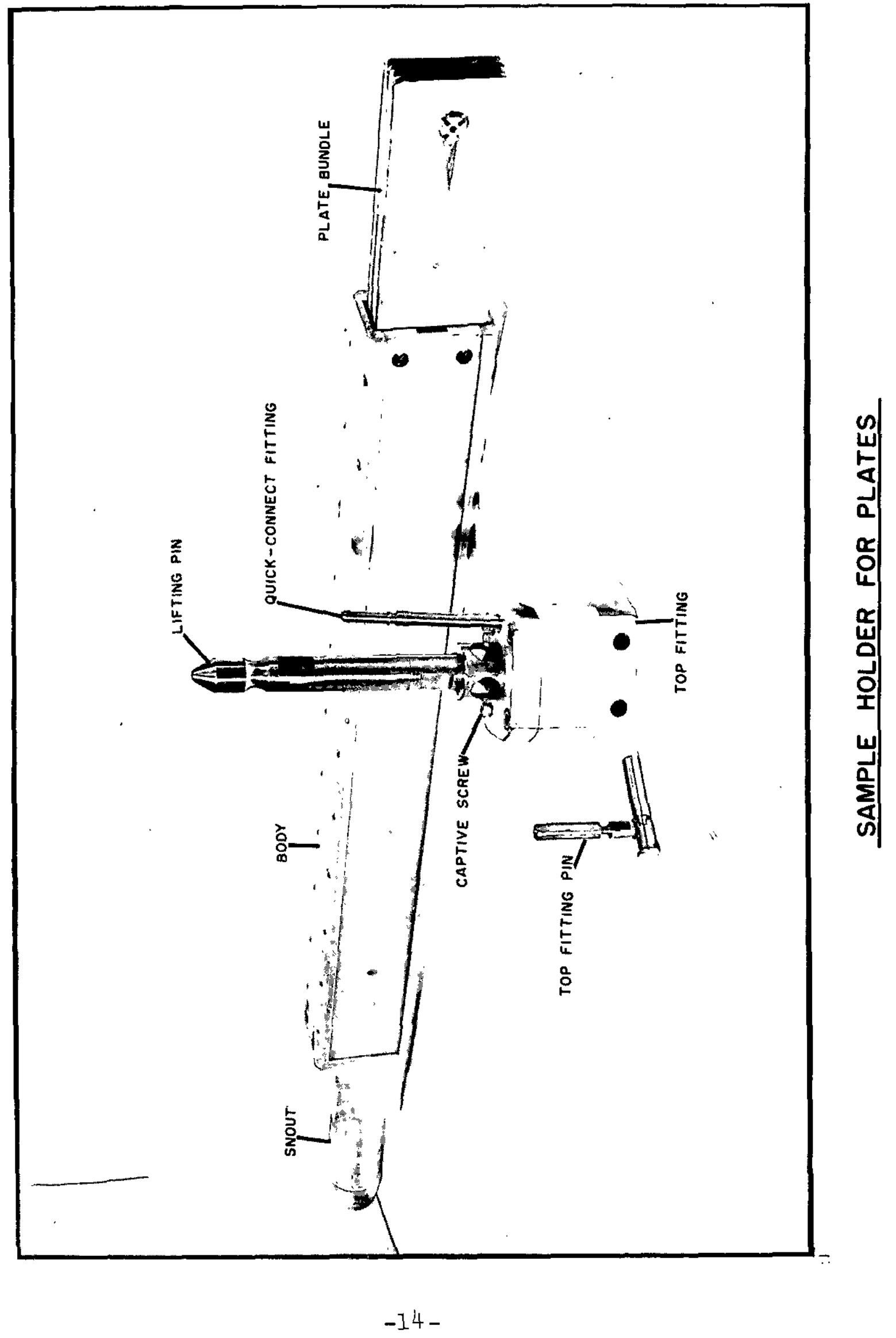




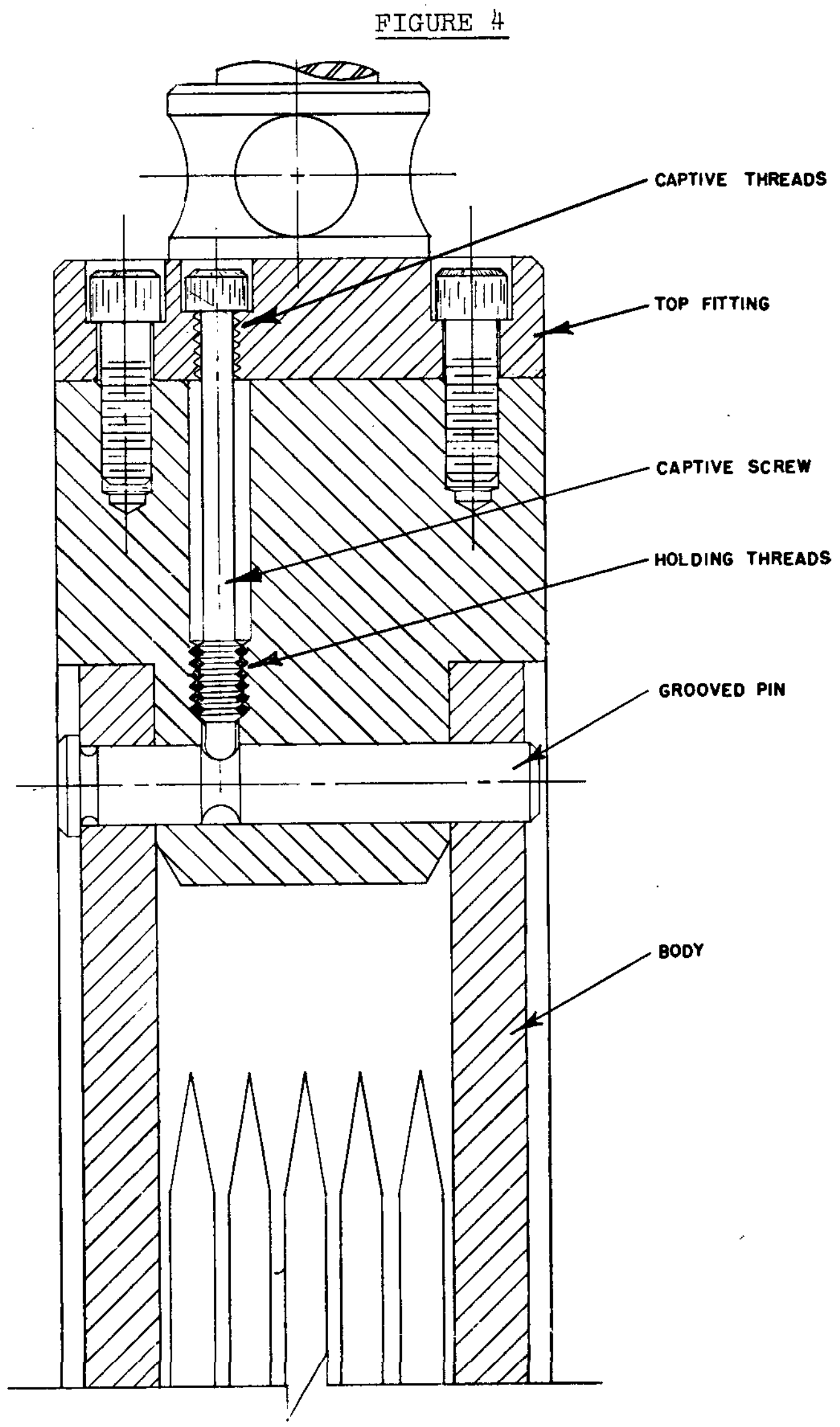

TOP FITTING PIN WITH CAPTIVE SCREW 


\section{FIGURE 5}

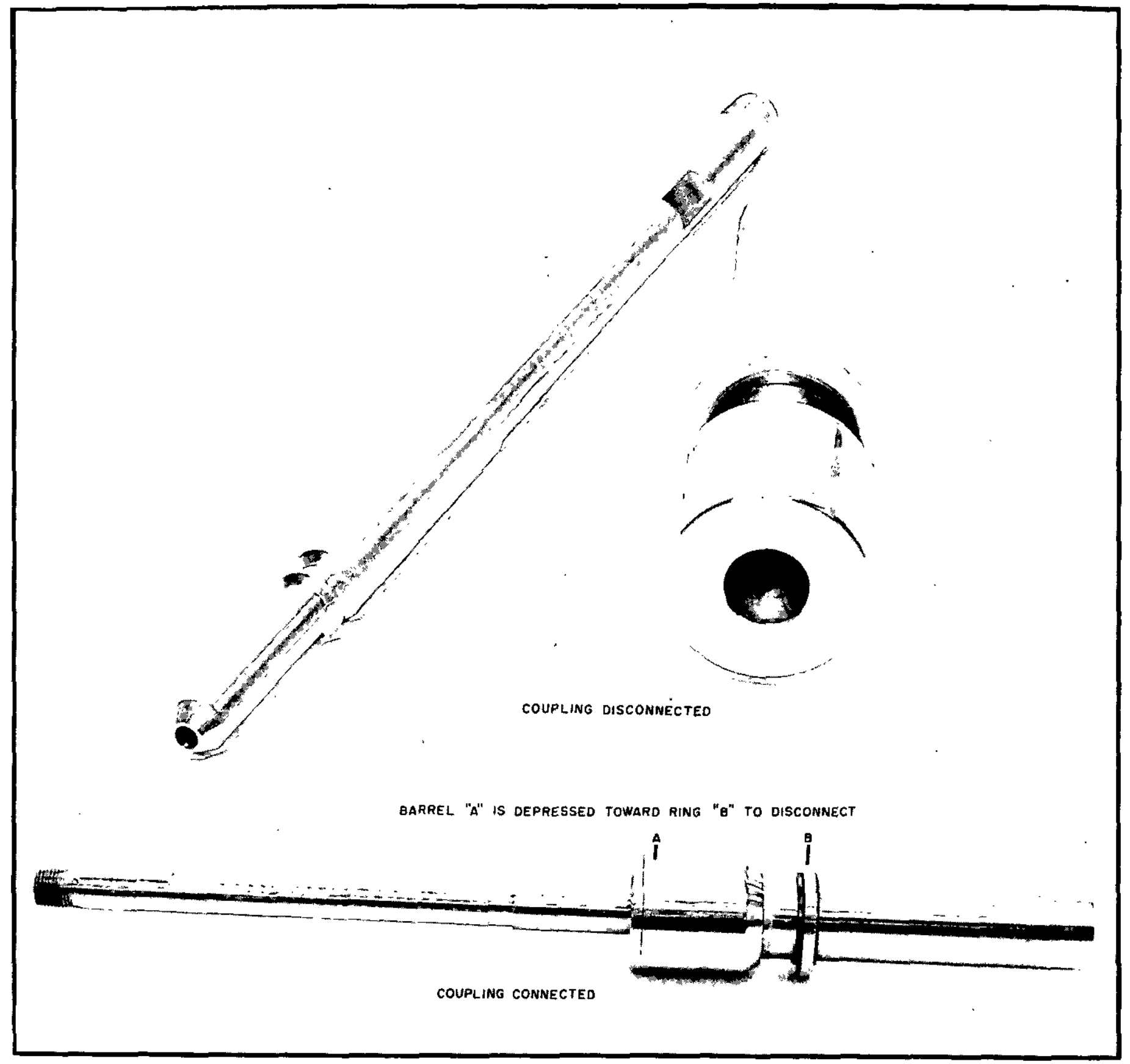

QUICK-CONNECT PRESSURE COUPLING 


\section{FIGURE 6}

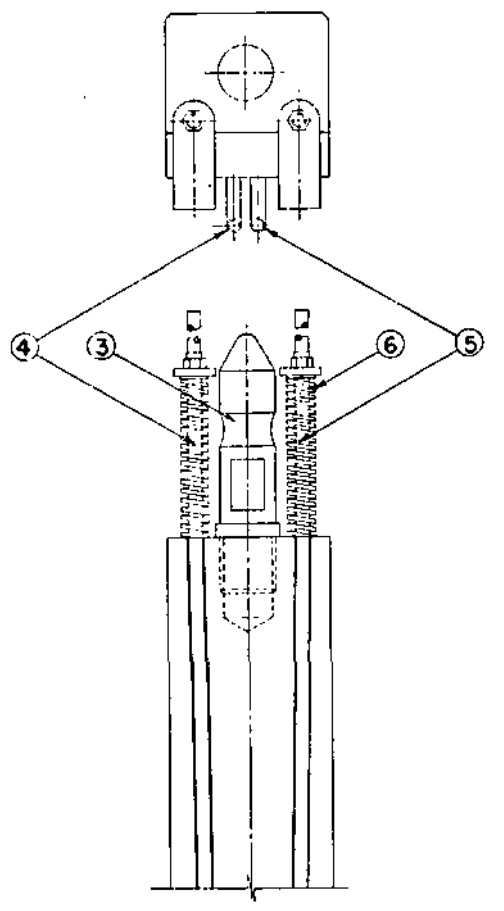

1- SNOUT

2- BOOY

3-LIFTING PIN

4- EFFLUENT SAMPLE PROBE

5 - THERMOCOUPLE PROBE

6 -PROBE SPRING

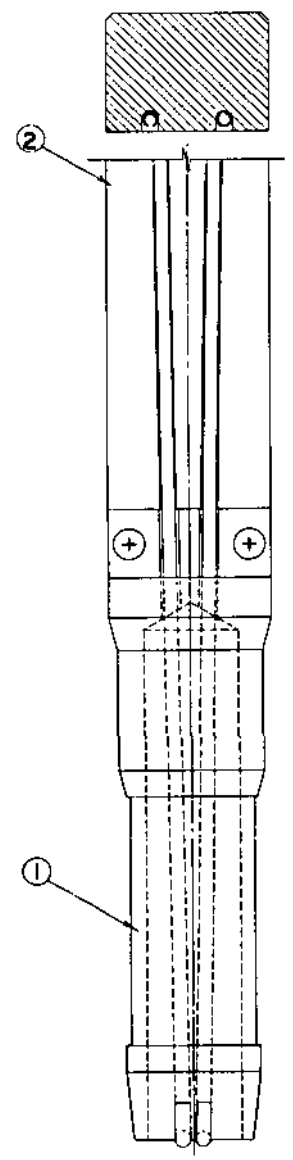

INSTRUMENT ASSEMBLY FOR PLATE SAMPLE HOLDER 


\section{FIGURE 7}
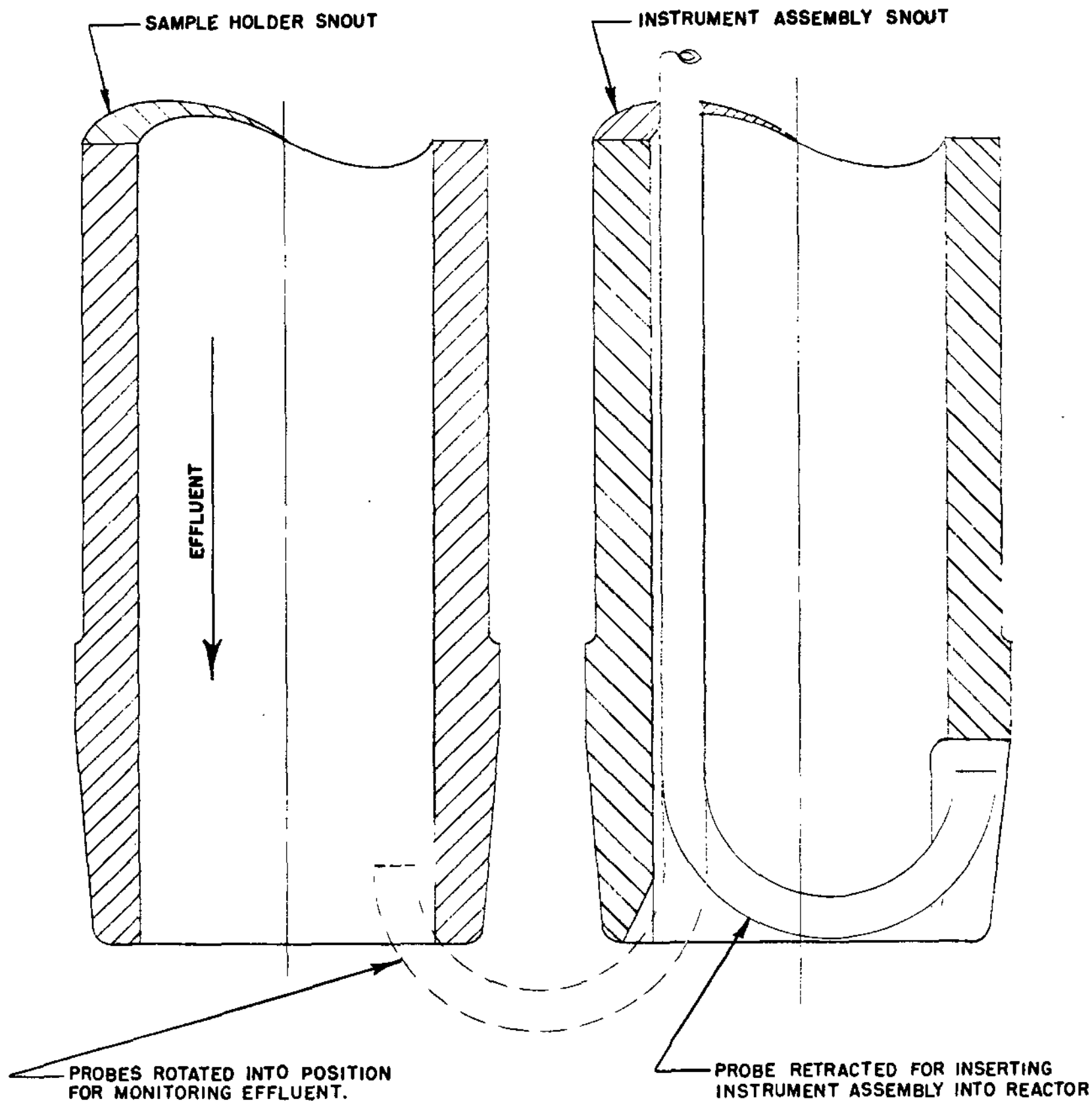

\section{ARRANGEMENT OF INSTRUMENT PROBES FOR MONITORING OF EFFLUENT FROM PLATE ELEMENTS}




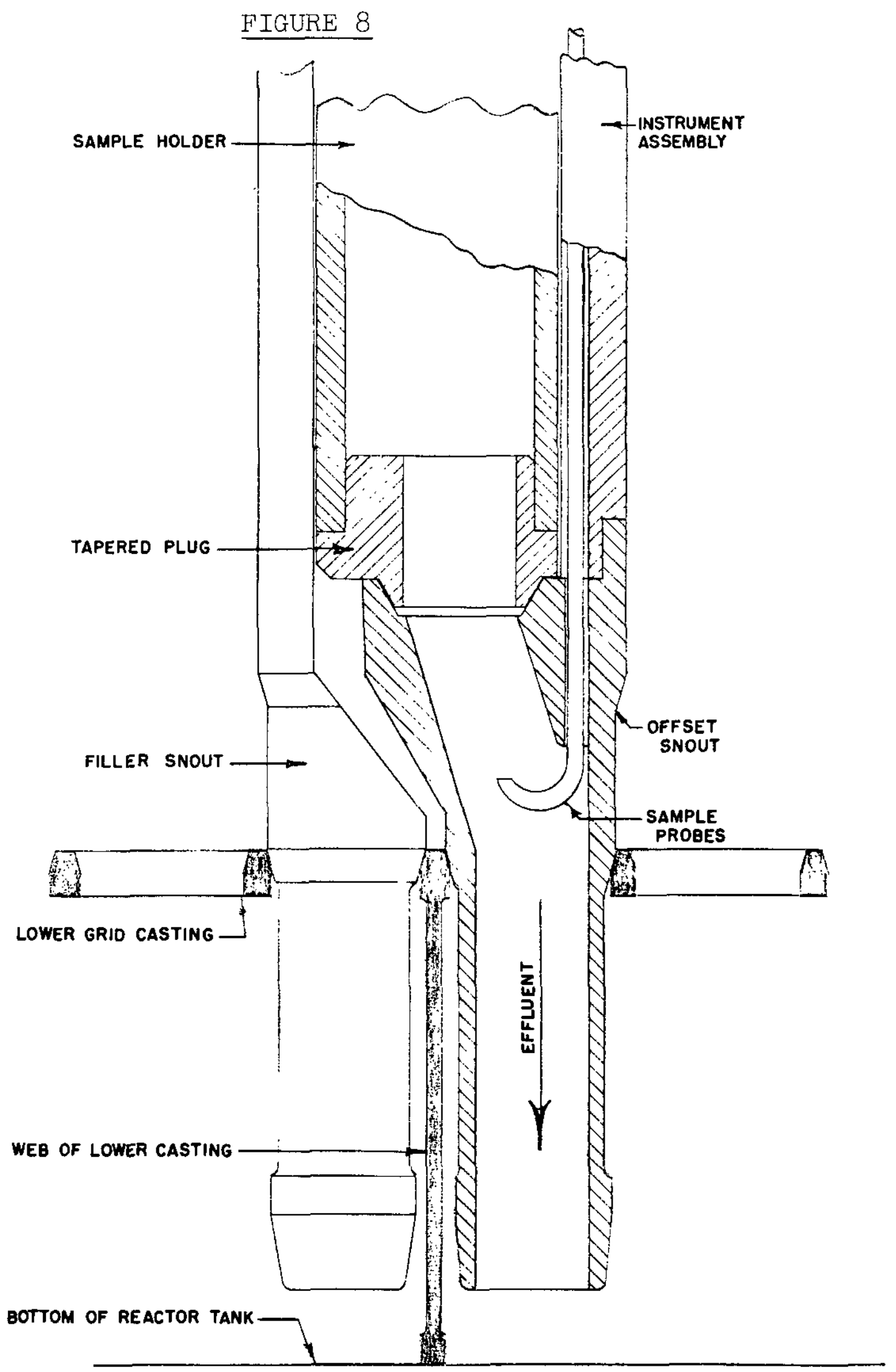

SOCKET ARRANGEMENT FOR MONITORING OF EFFLUENT FROM PLATE ELEMENTS 


\section{FIGURE 9}

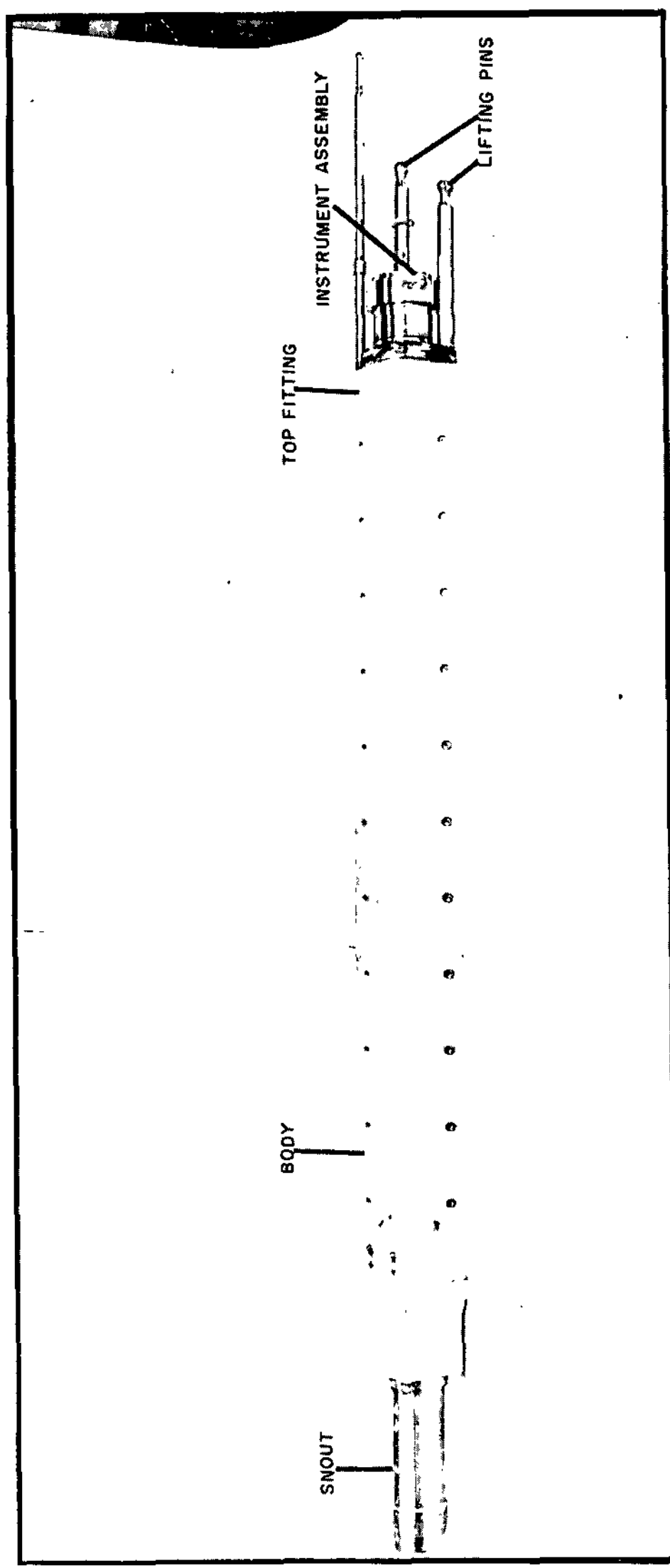

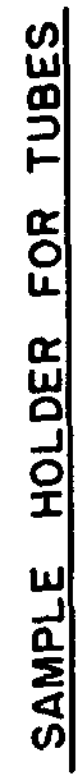


FIGURE 10

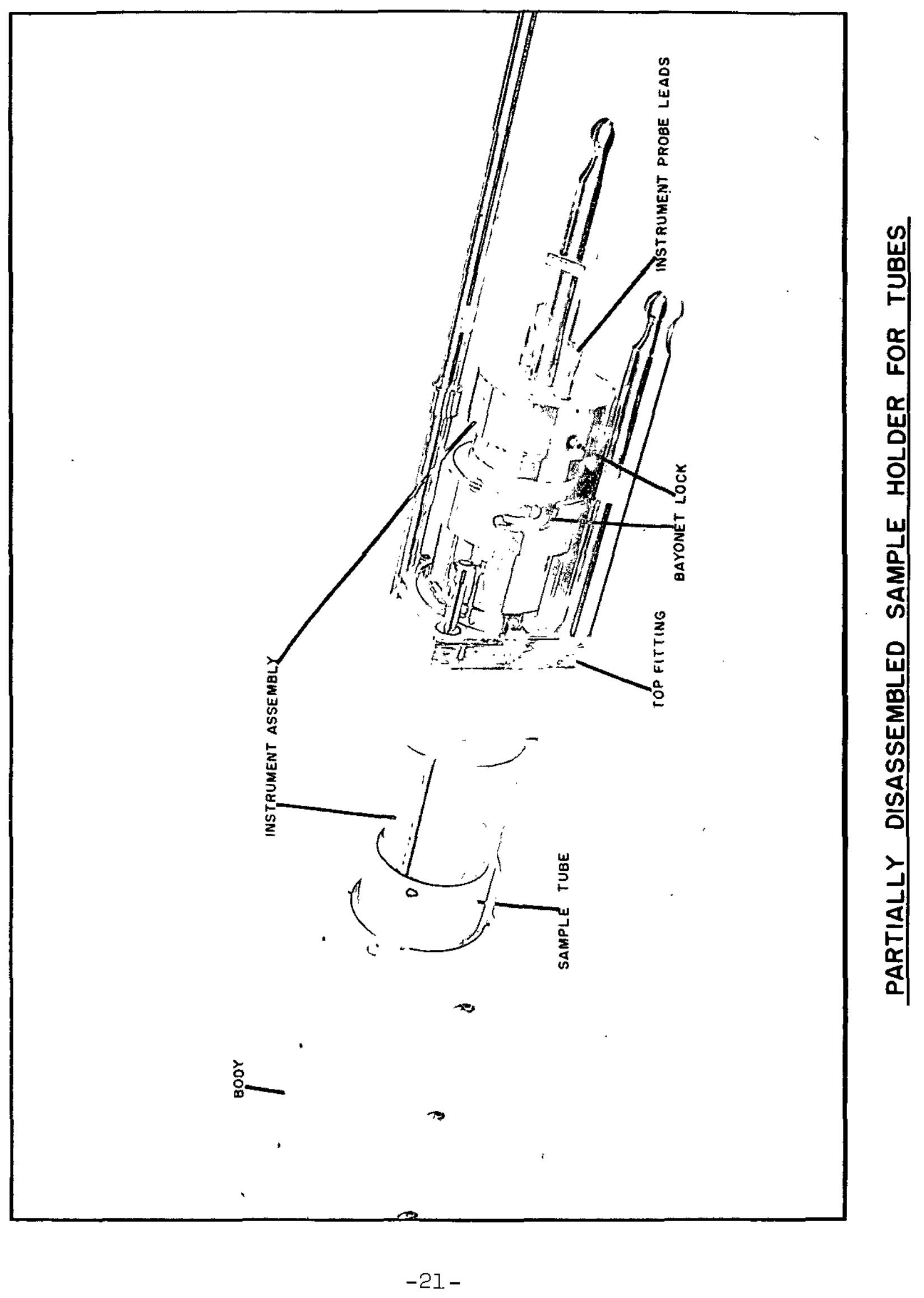




\section{FIGURE 11}

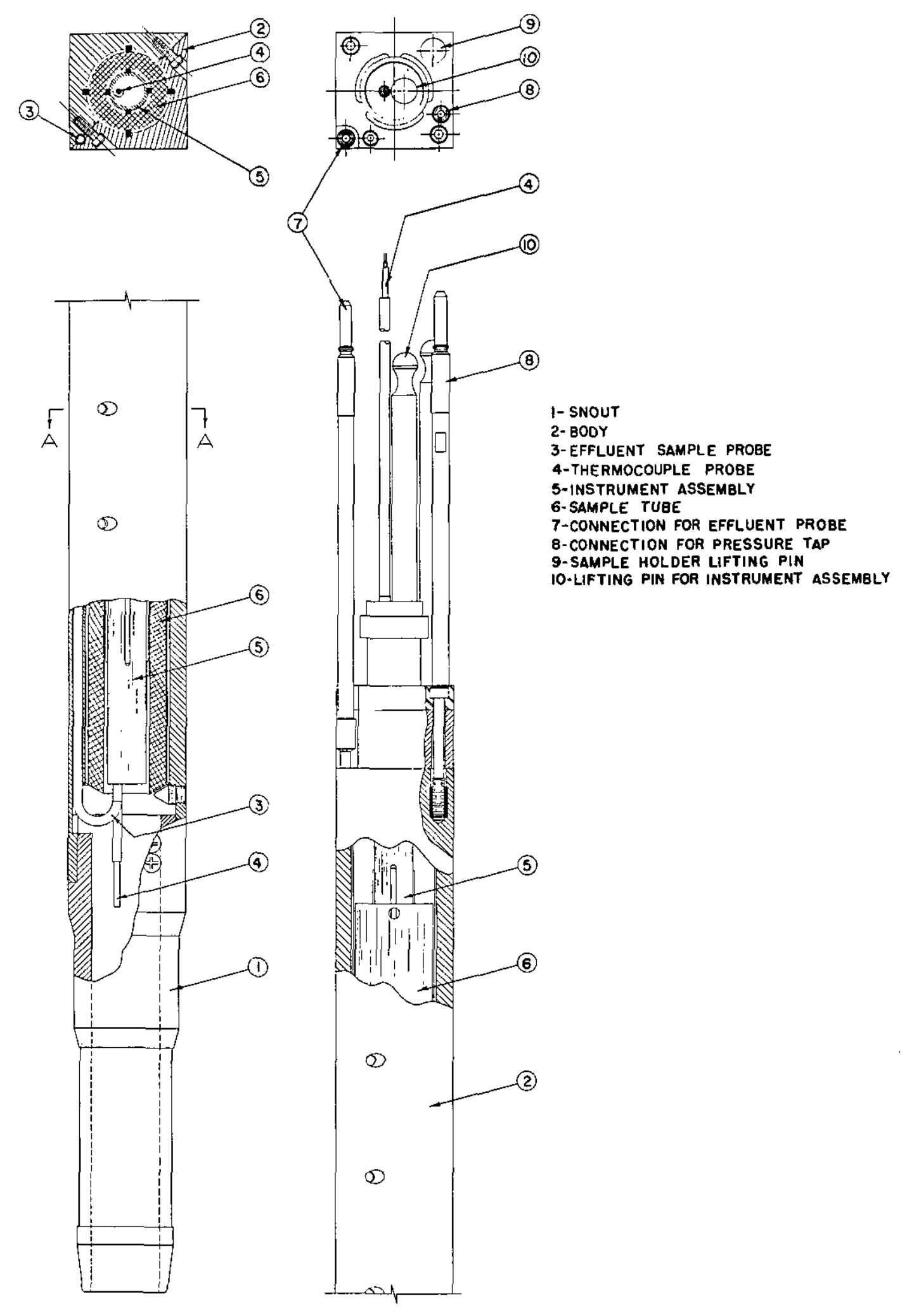

SAMPLE HOLDER FOR TUBES WITH SMALL INSIDE DIAMETER 


\section{FIGURE 12}
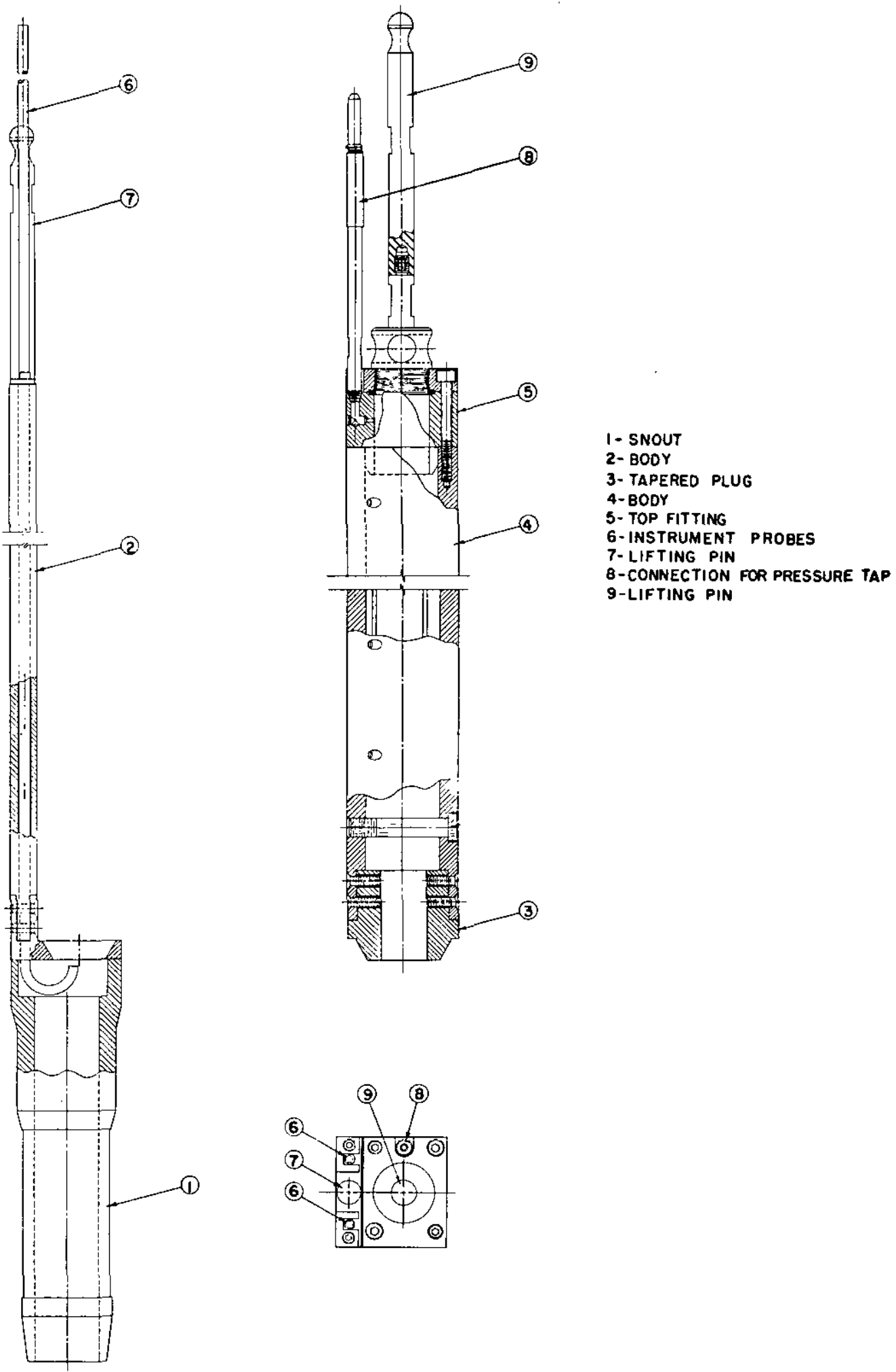

SAMPLE HOLDER \& INSTRUMENT ASSEMBLY FOR CYLINDERS 


\section{APPENDIX}

The following detail drawings of the equipment are included:

EXHIBIT NO.

1

2

3

4

5

6

10

11

12

13

14

15
TITLE

Assembly Sample Plate Holder

"T" Sample Holder Assembly

Instrument Tube Assembly

Main Body "T" Sample Holder

Top Fitting for "T" Sample Holder

Bottom Snout for "T" Sample Holder

Tube for MTR Test

Instrument Tube and Water Sample Tube

Main Body of Sample Holder

Top Fitting and Pressure Connector

Bottom Snout

Top Fittings and Parts

Sample Box

Sample Box Details I

Sample Box Details II 


\section{EXHIBIT 1}

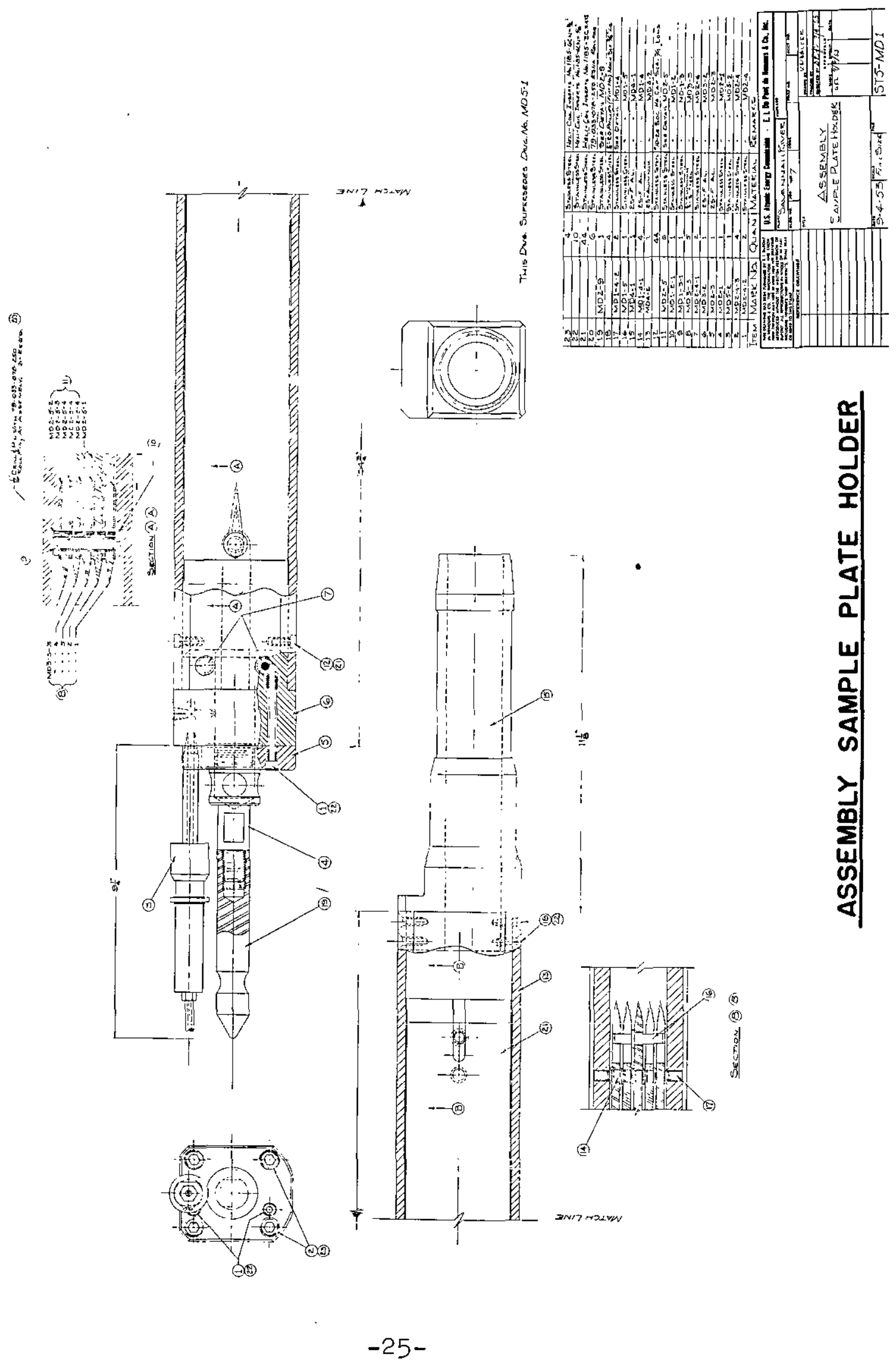




\section{EXHIBIT 2}
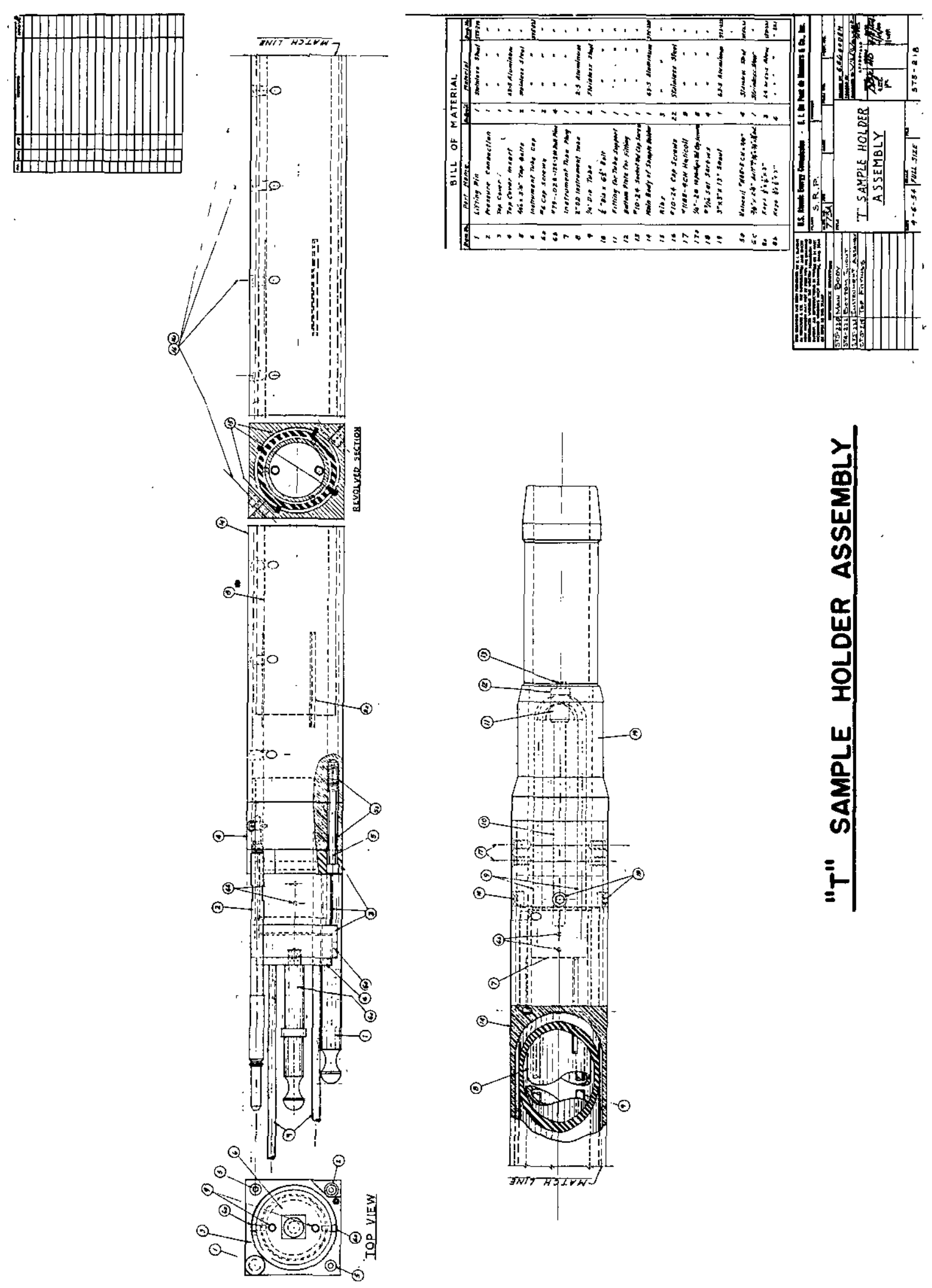
EXHIBIT 3

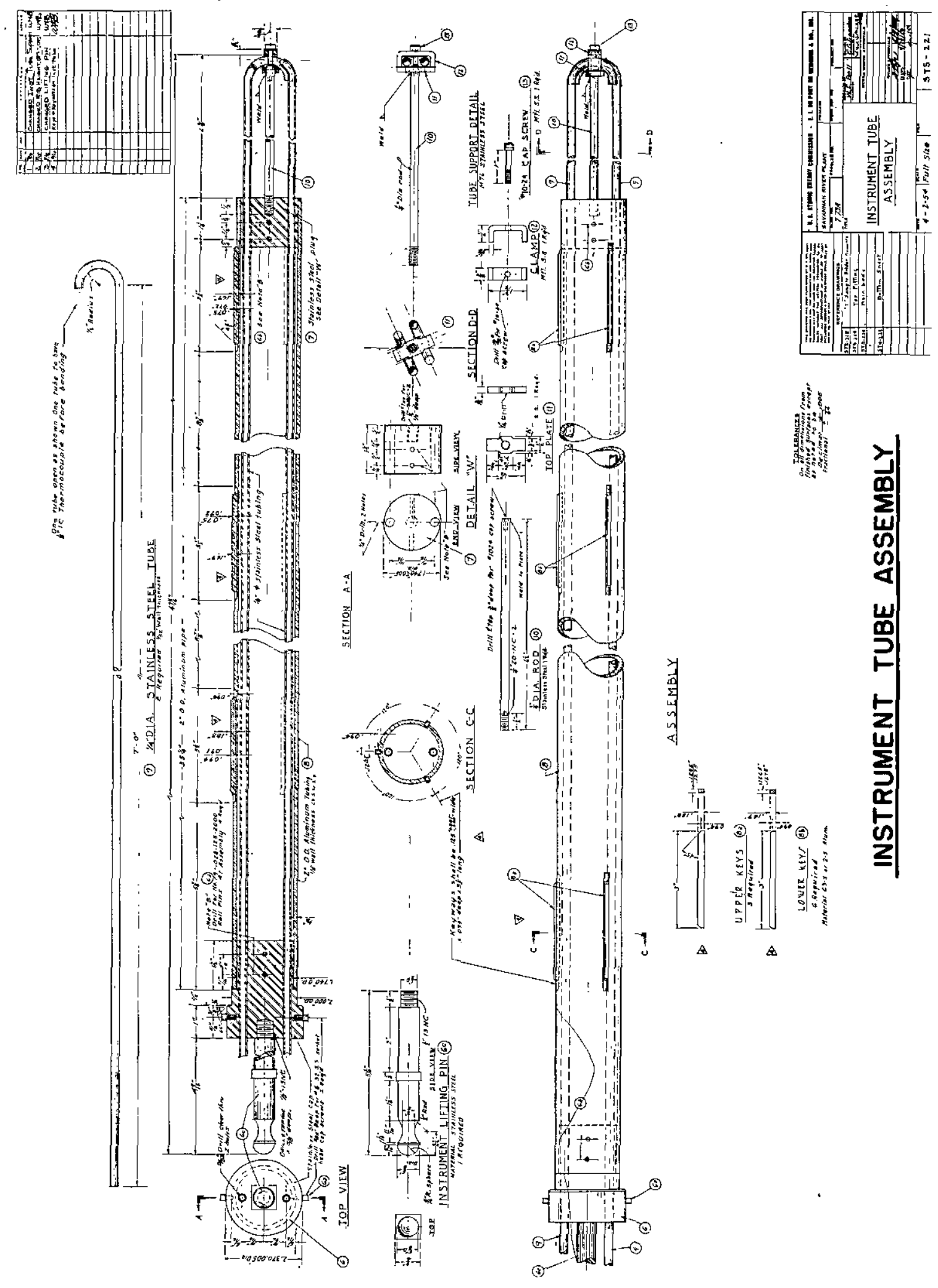




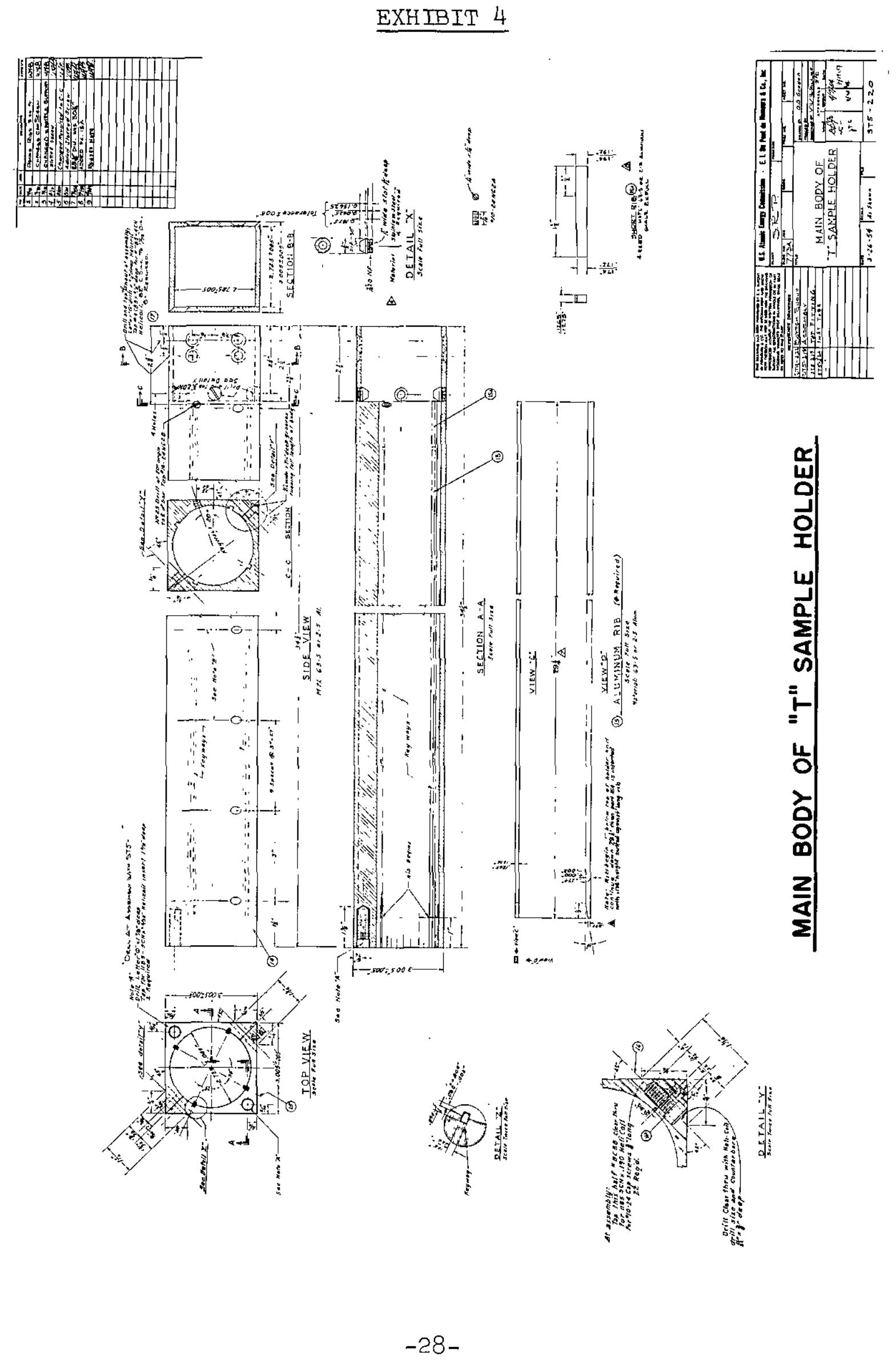


EXHIBIT 5
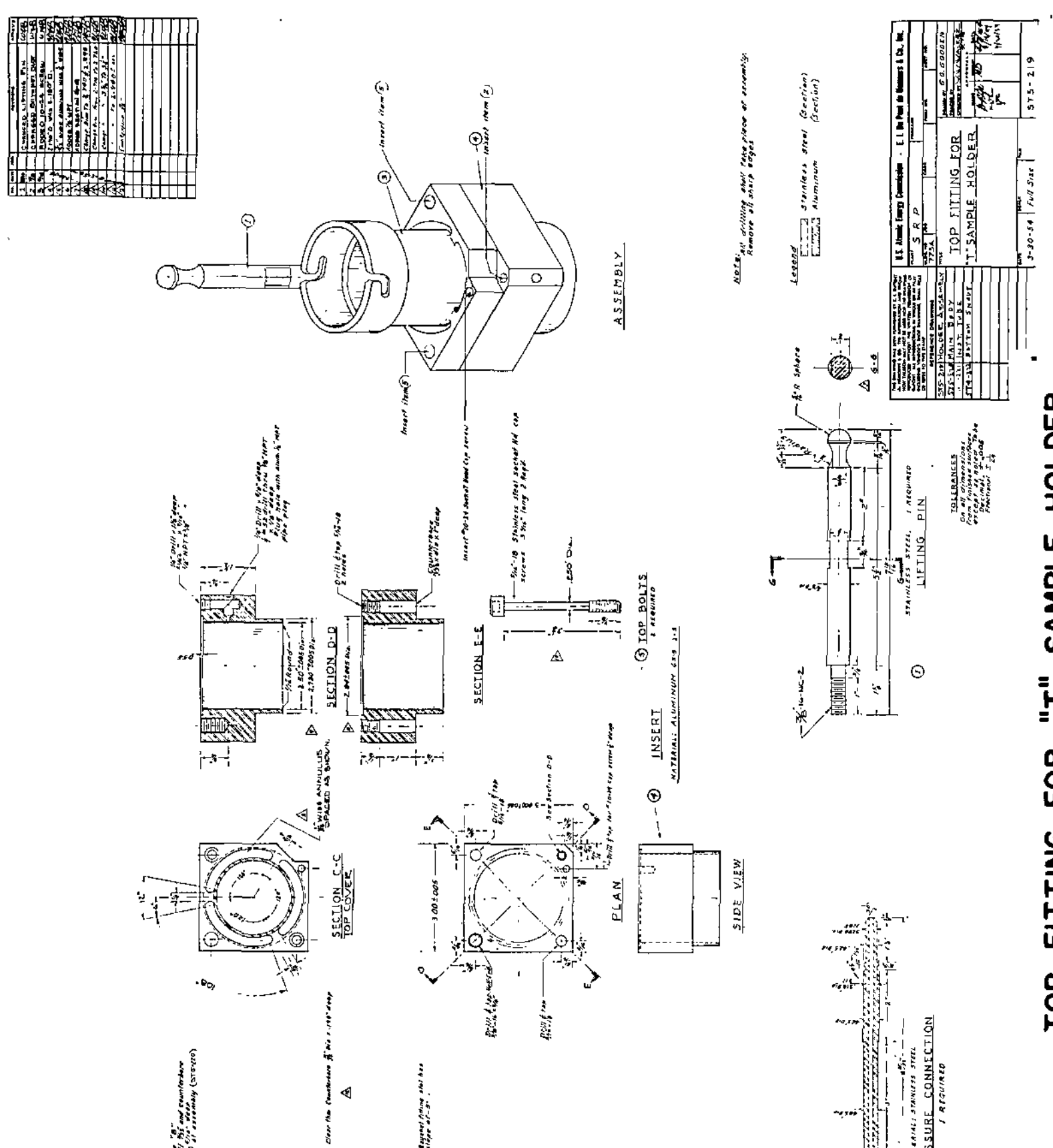

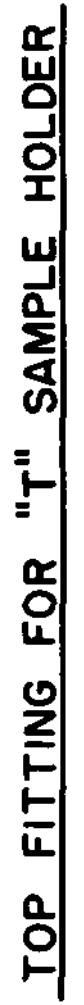


EXHIBIT 6
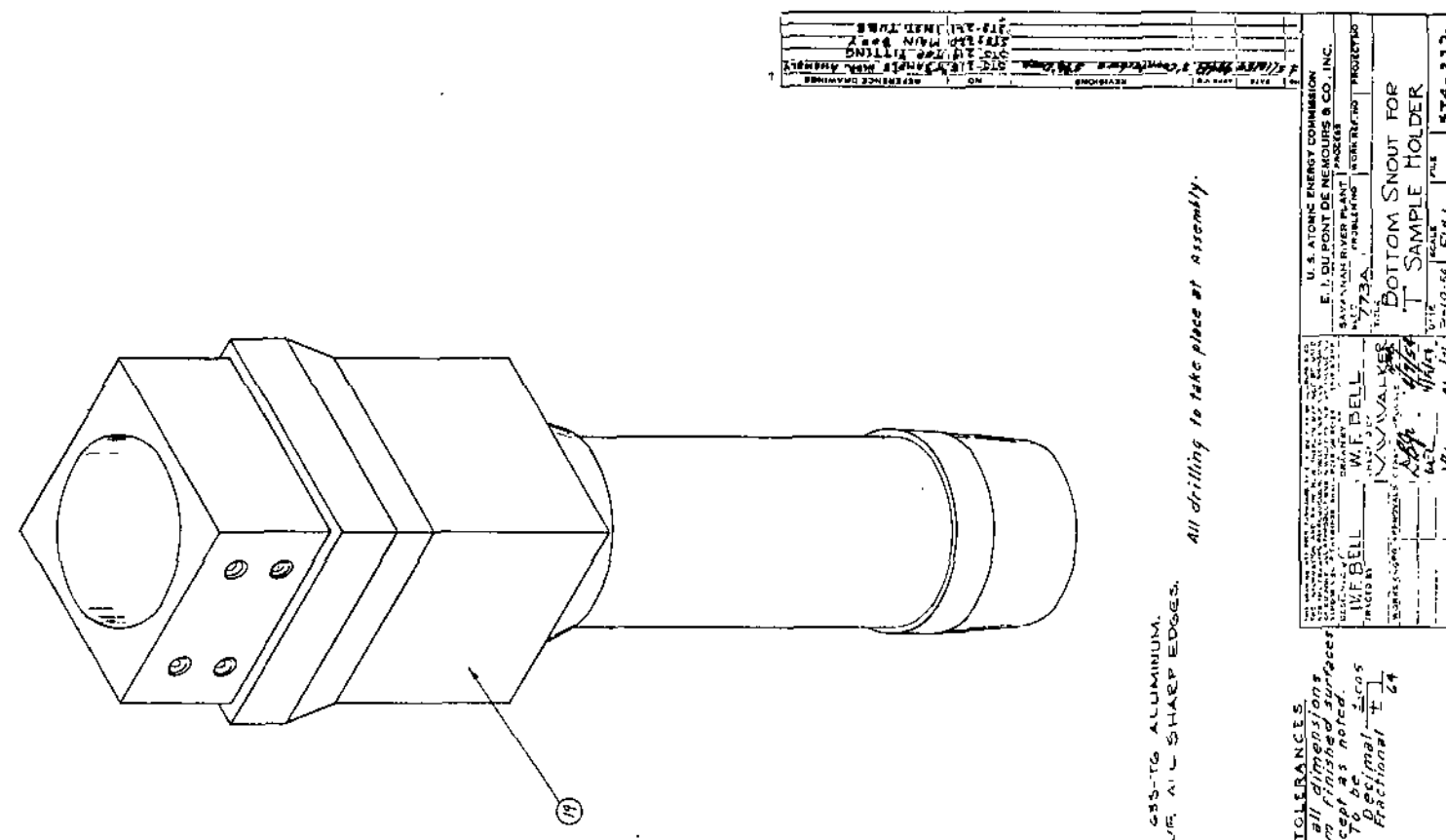

on

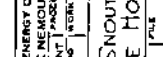

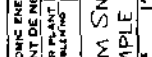

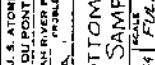

की

$\frac{1}{1}$

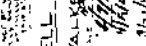

mo

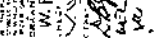
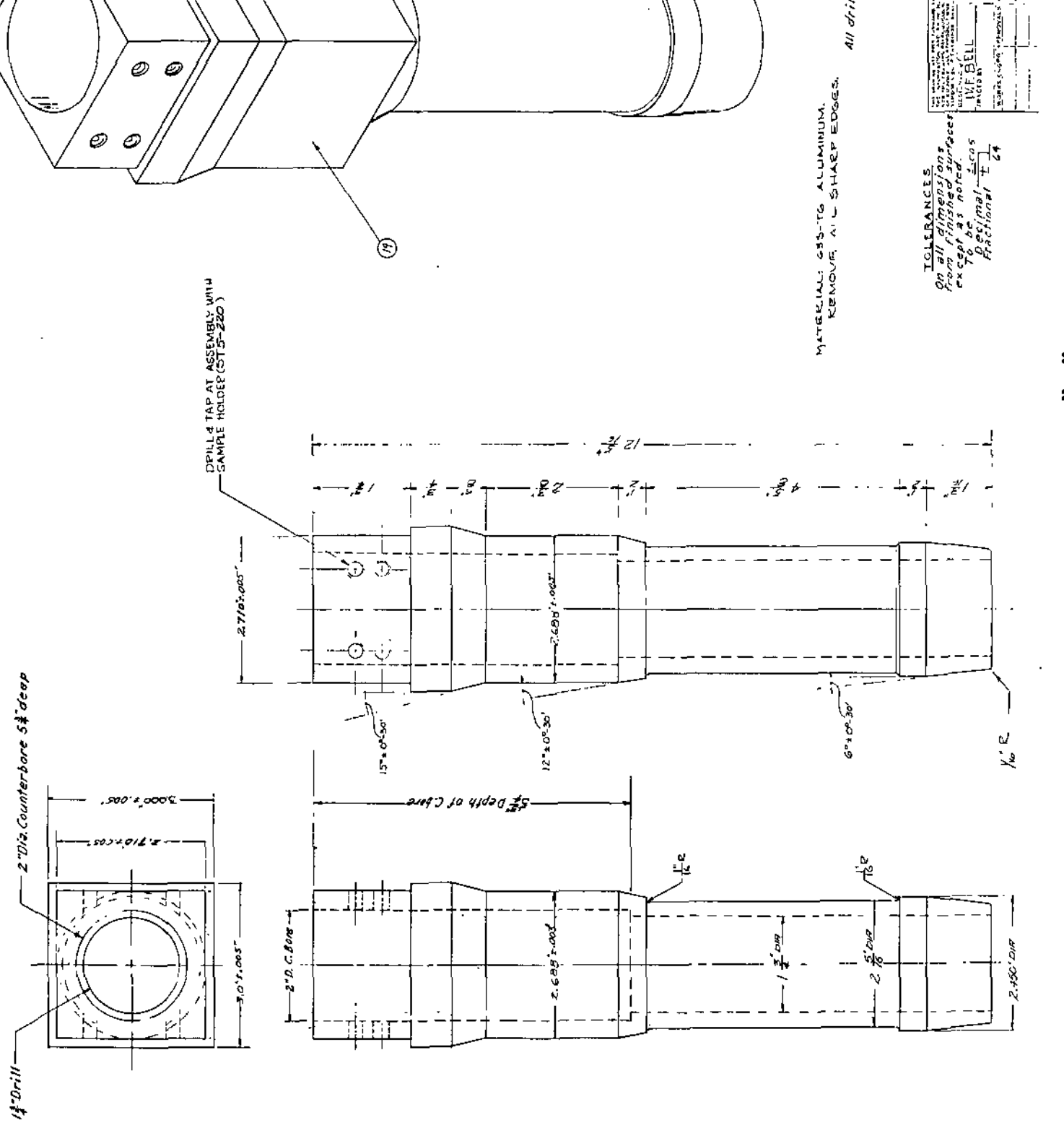

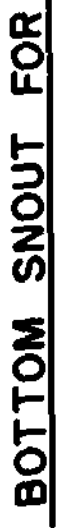
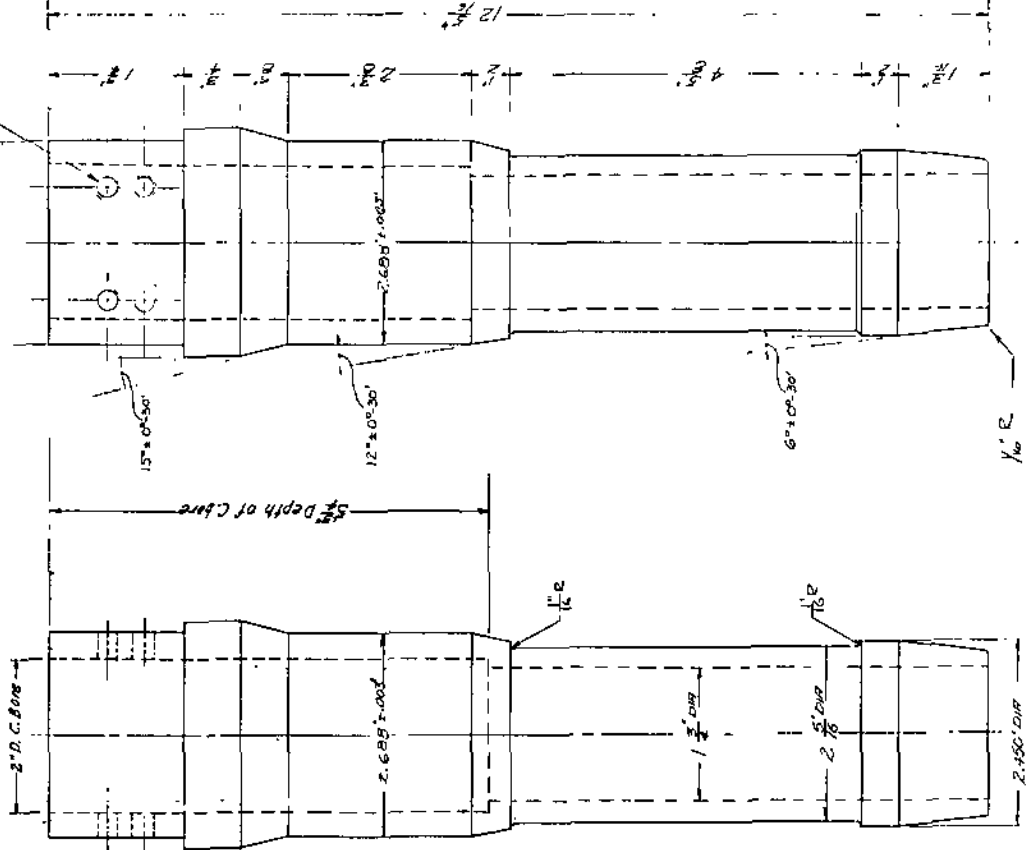


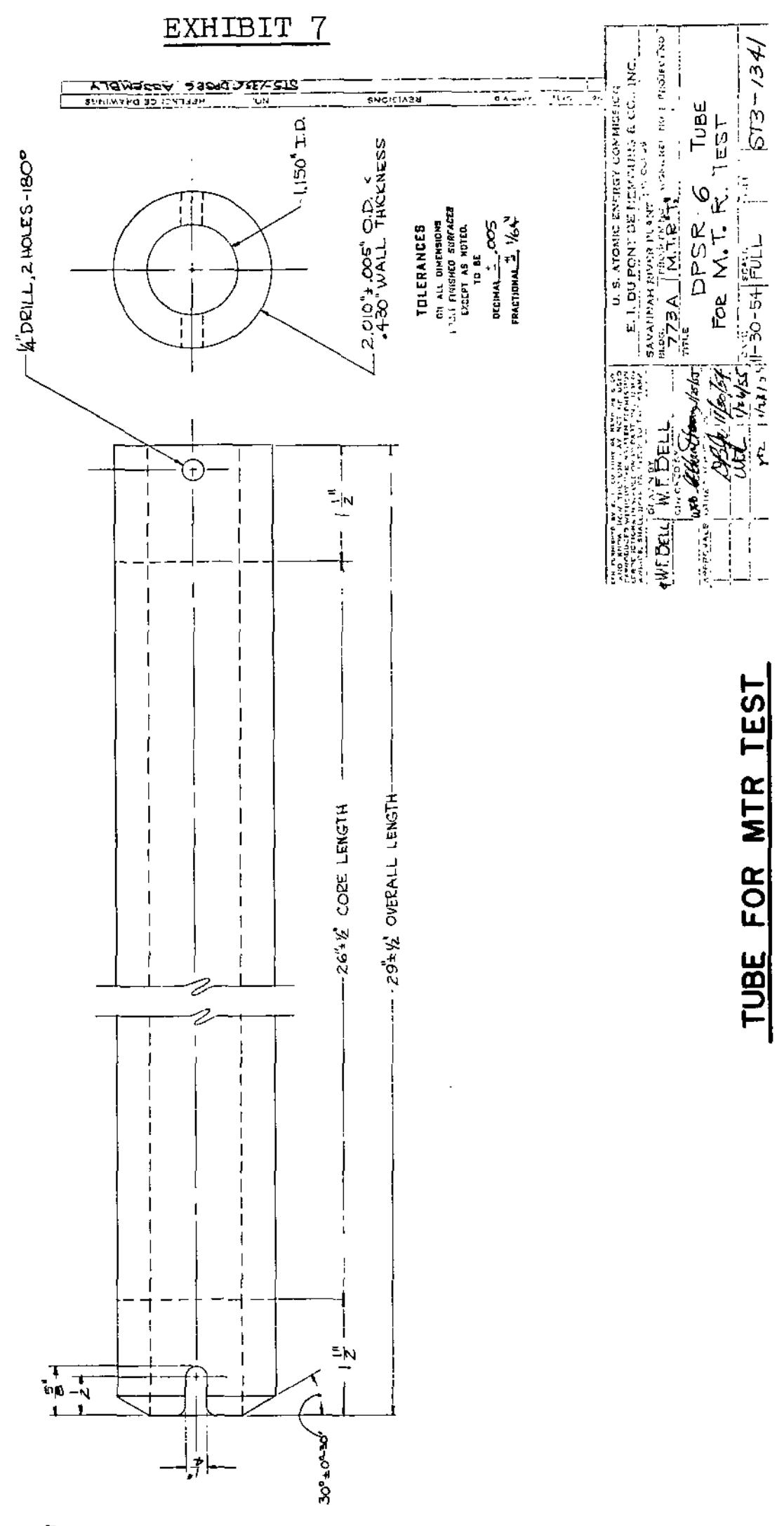


EXHIBIT 8
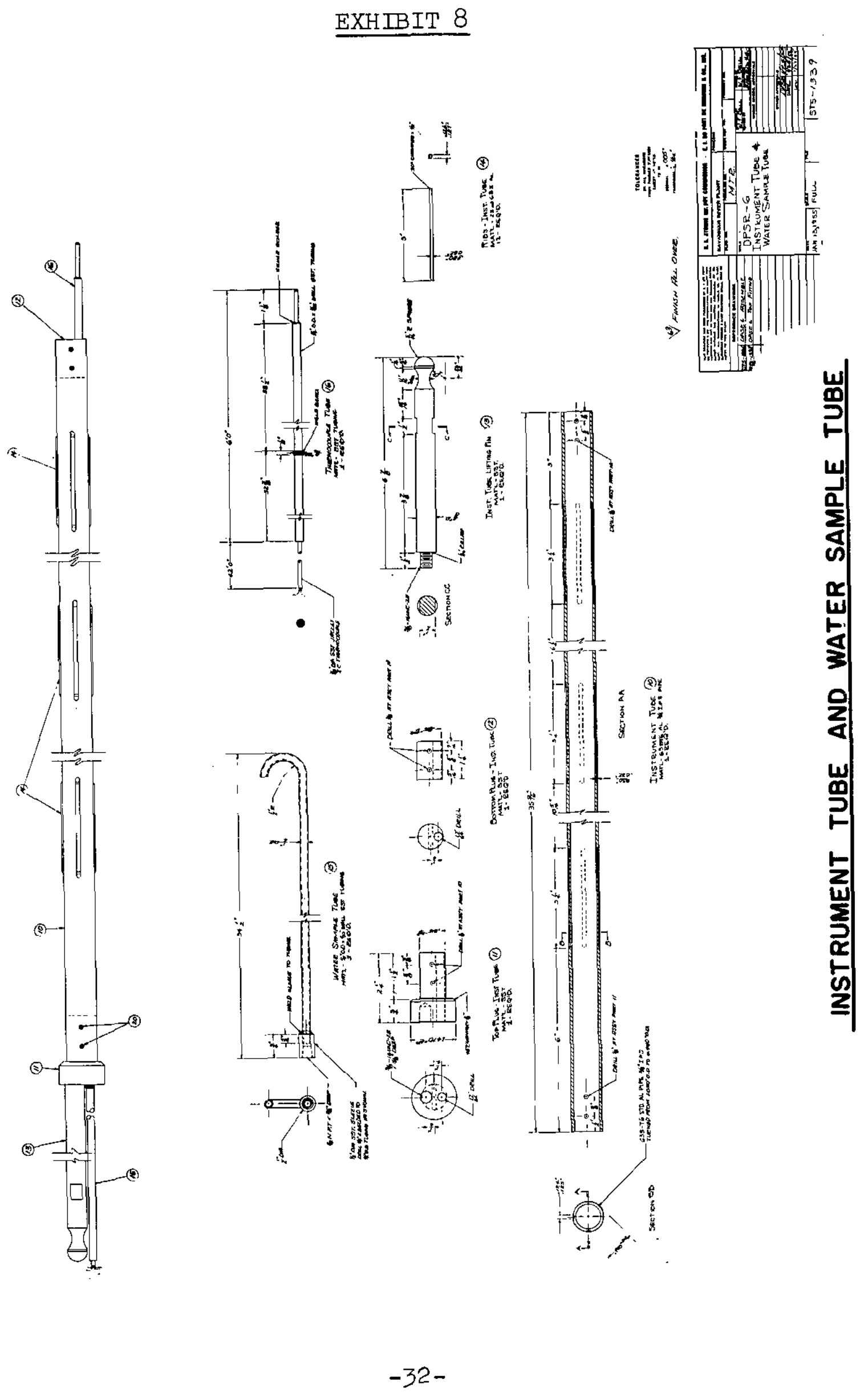


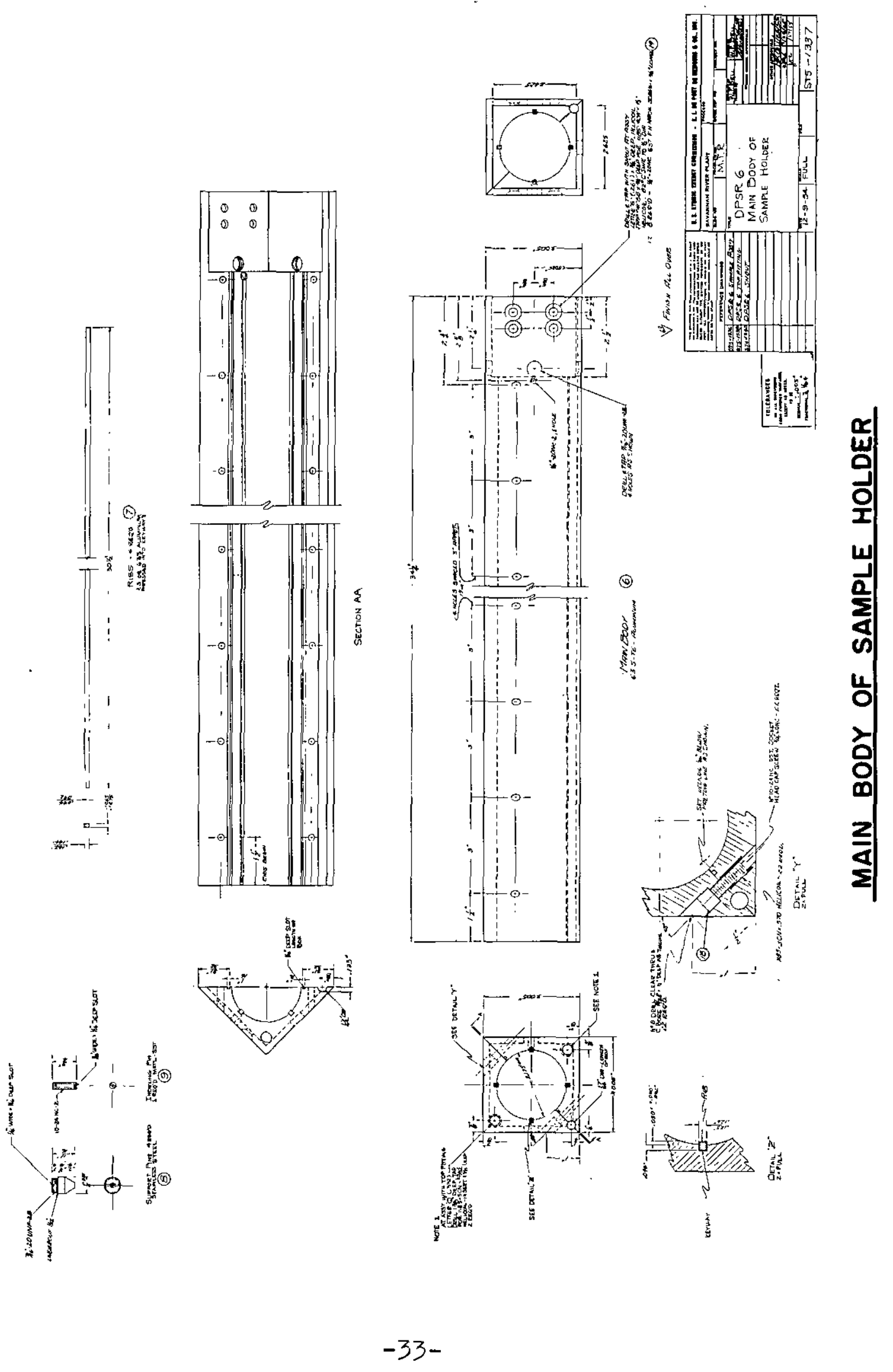




\section{EXHIBIT 10}

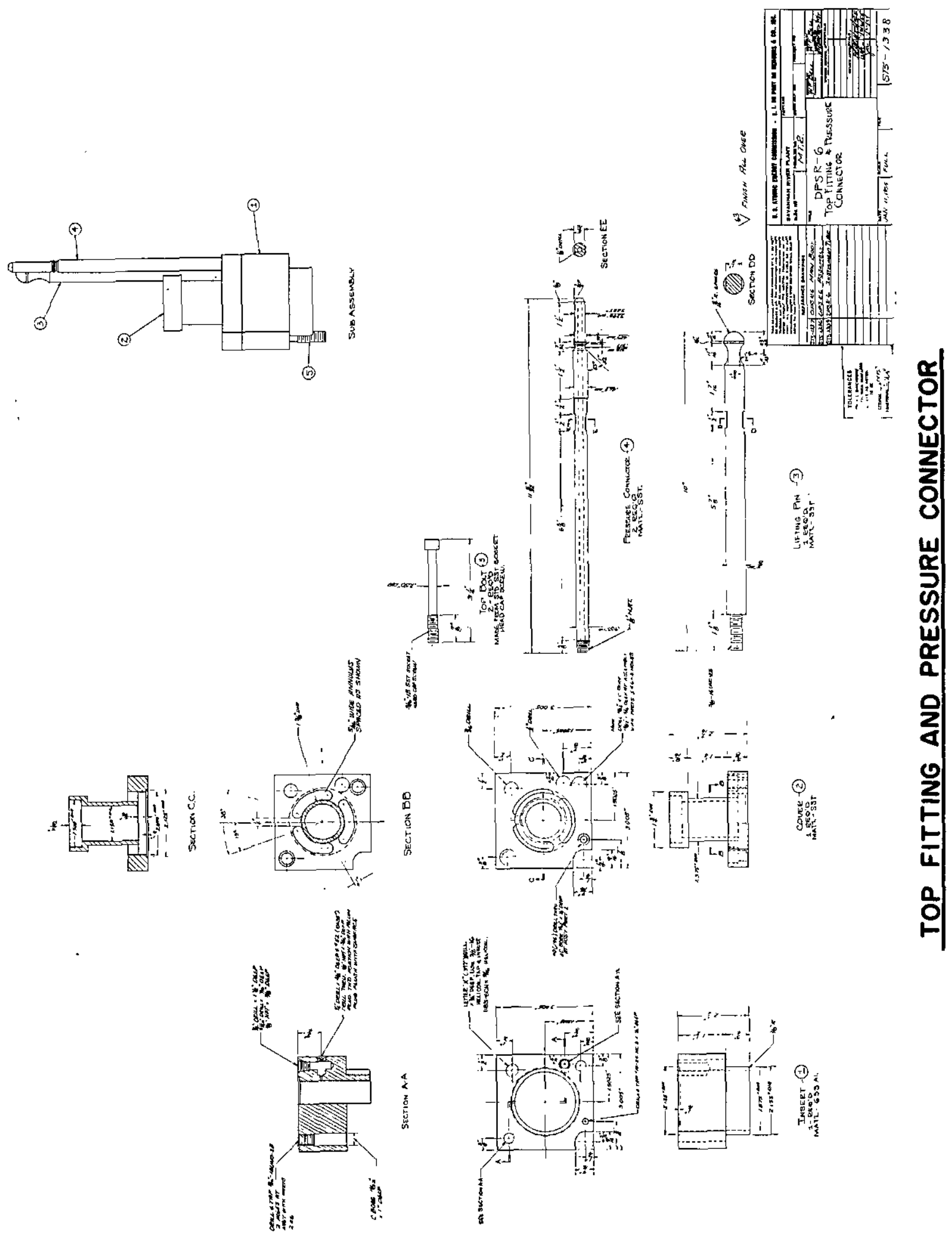




\section{EXHIBIT 11}
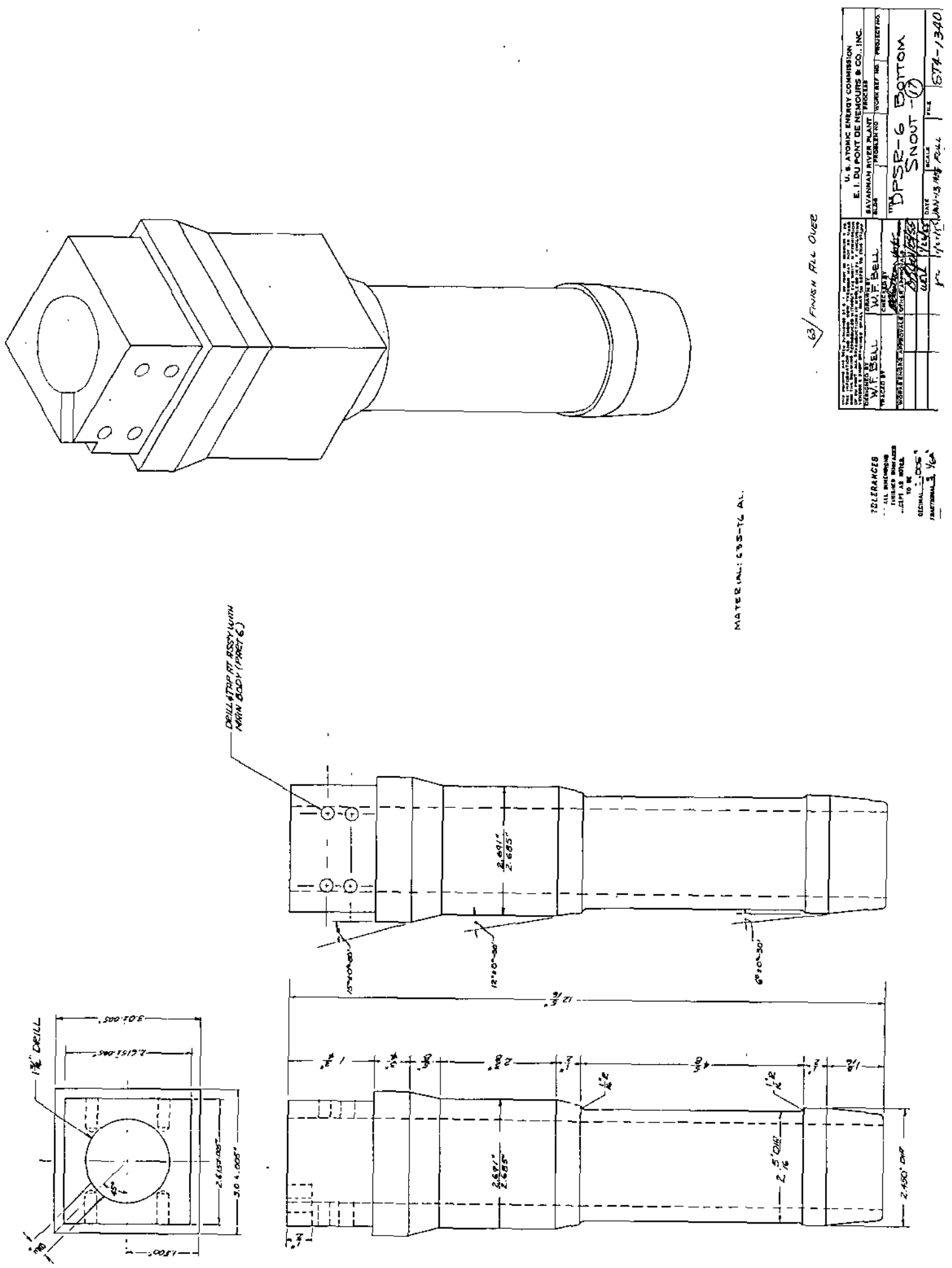

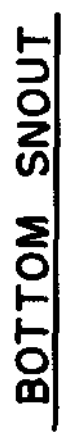
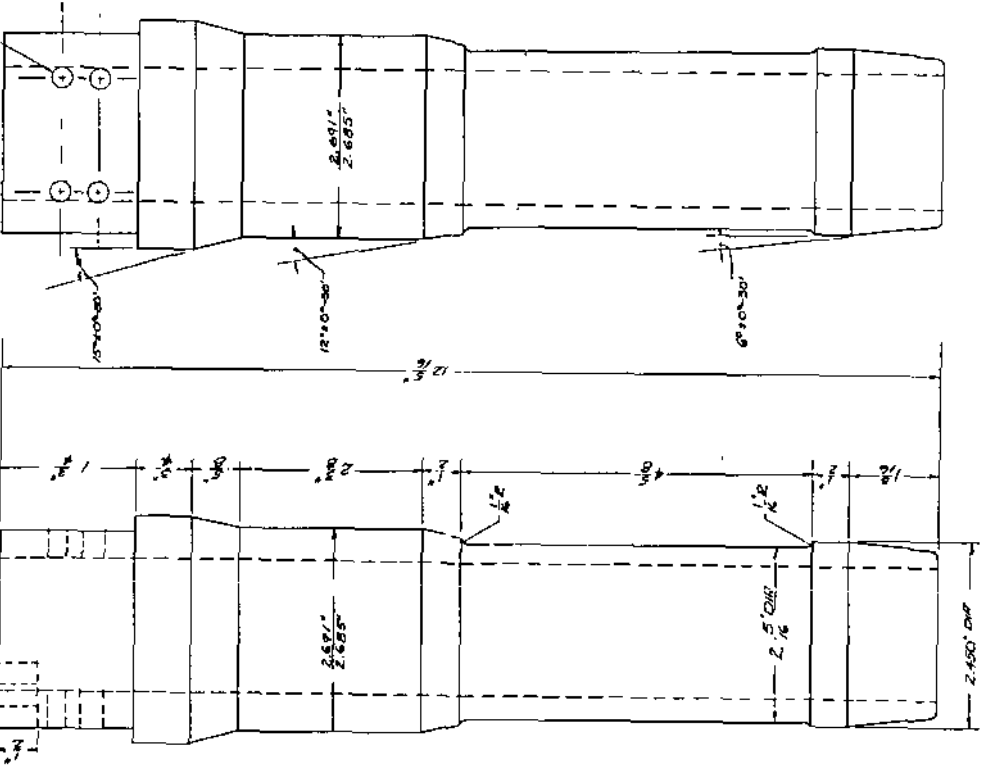
EXHIBIT 12
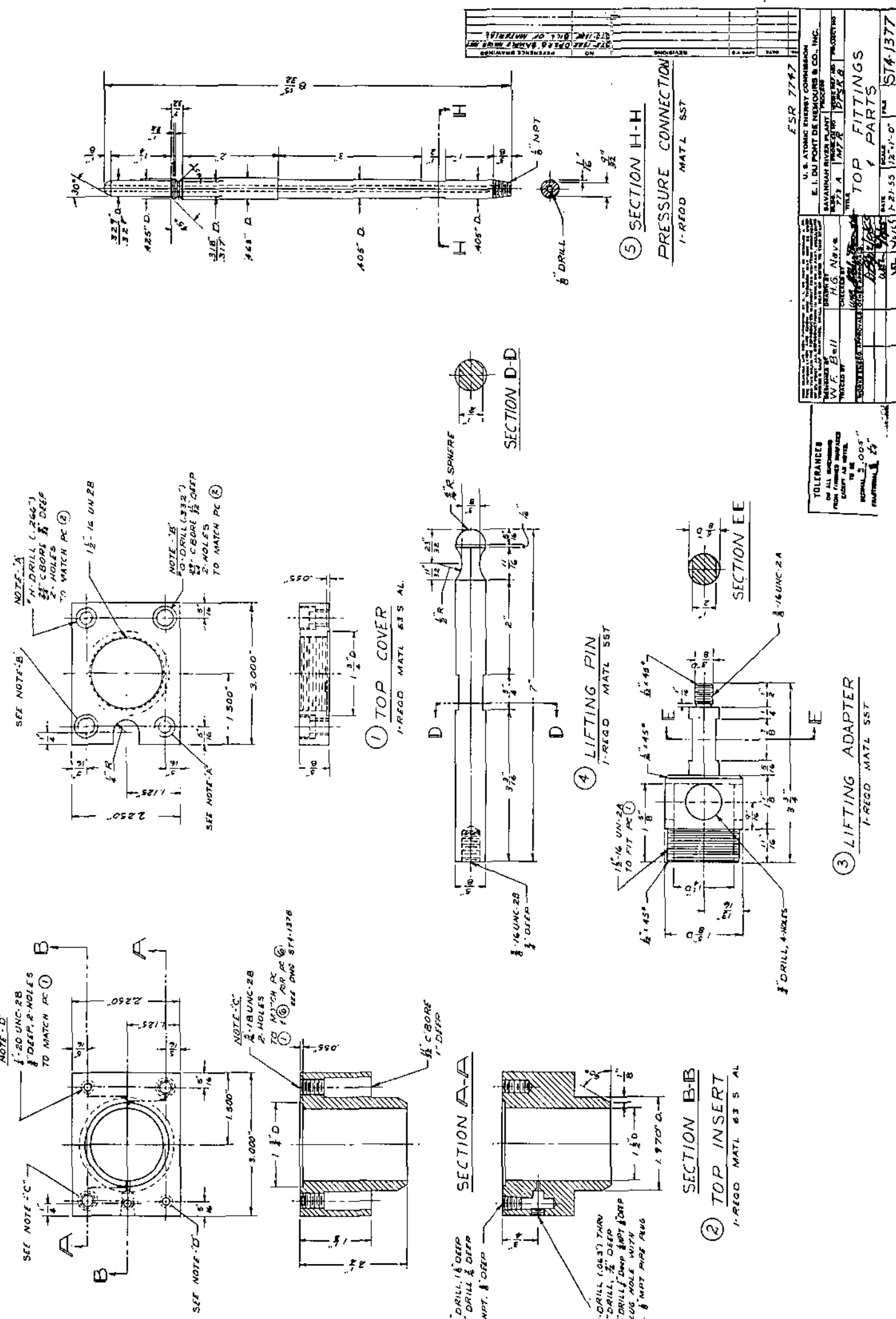

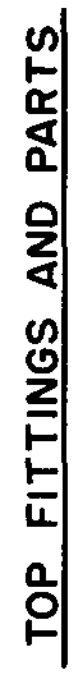




\section{EXHIBIT 13}

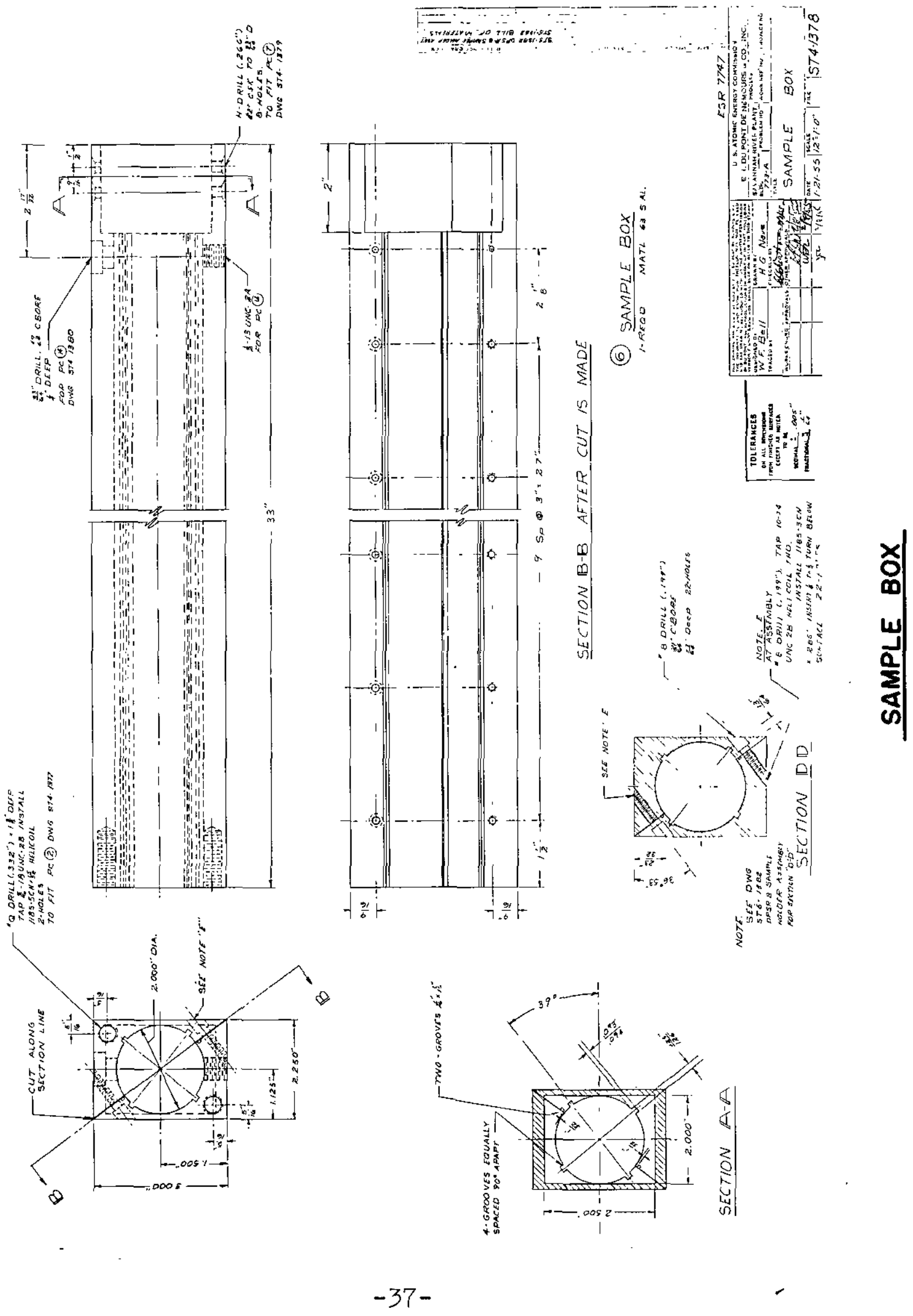


EXHIBIT 14
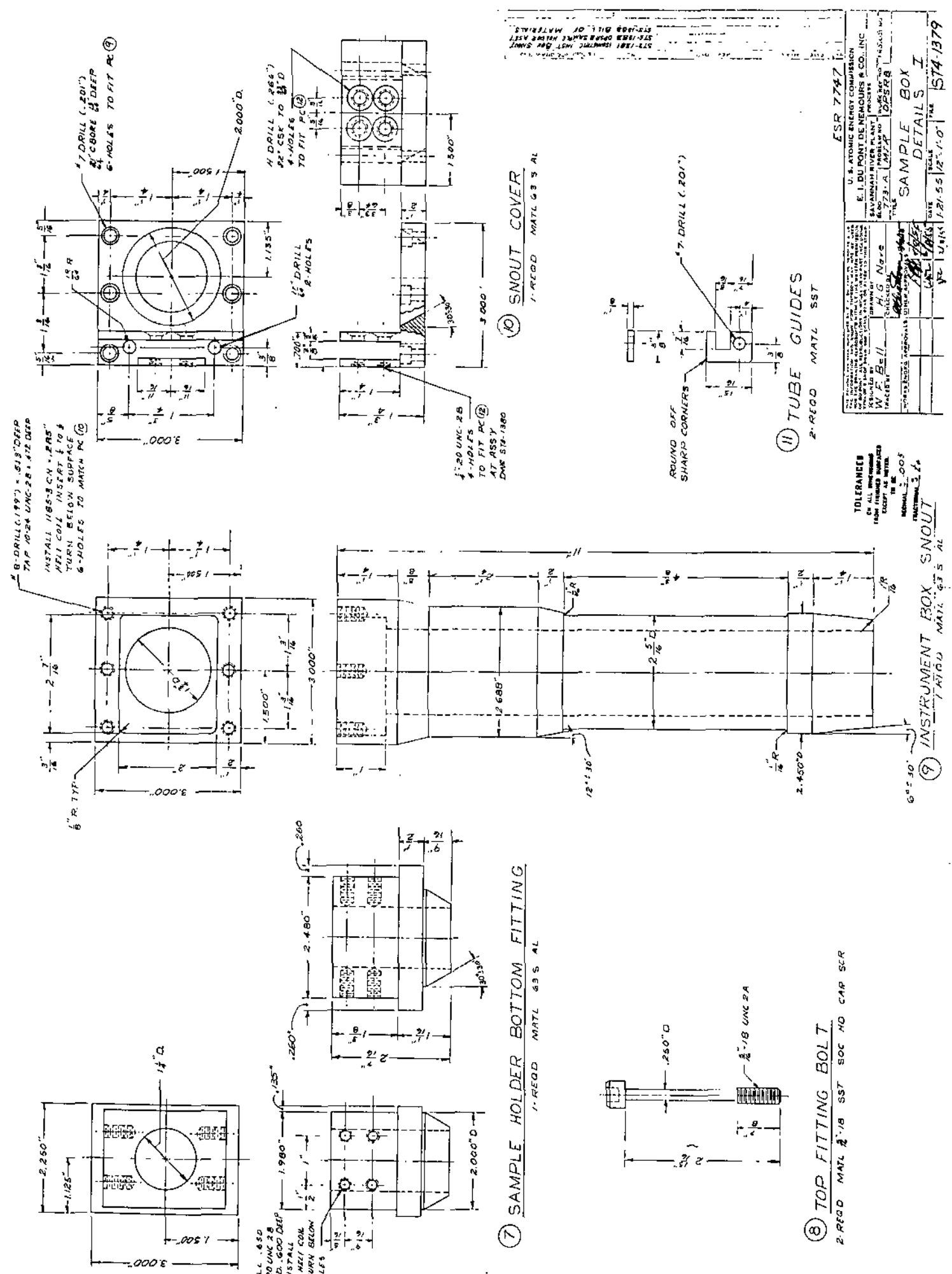

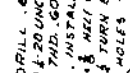

0

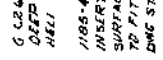


EXHIBIT 15

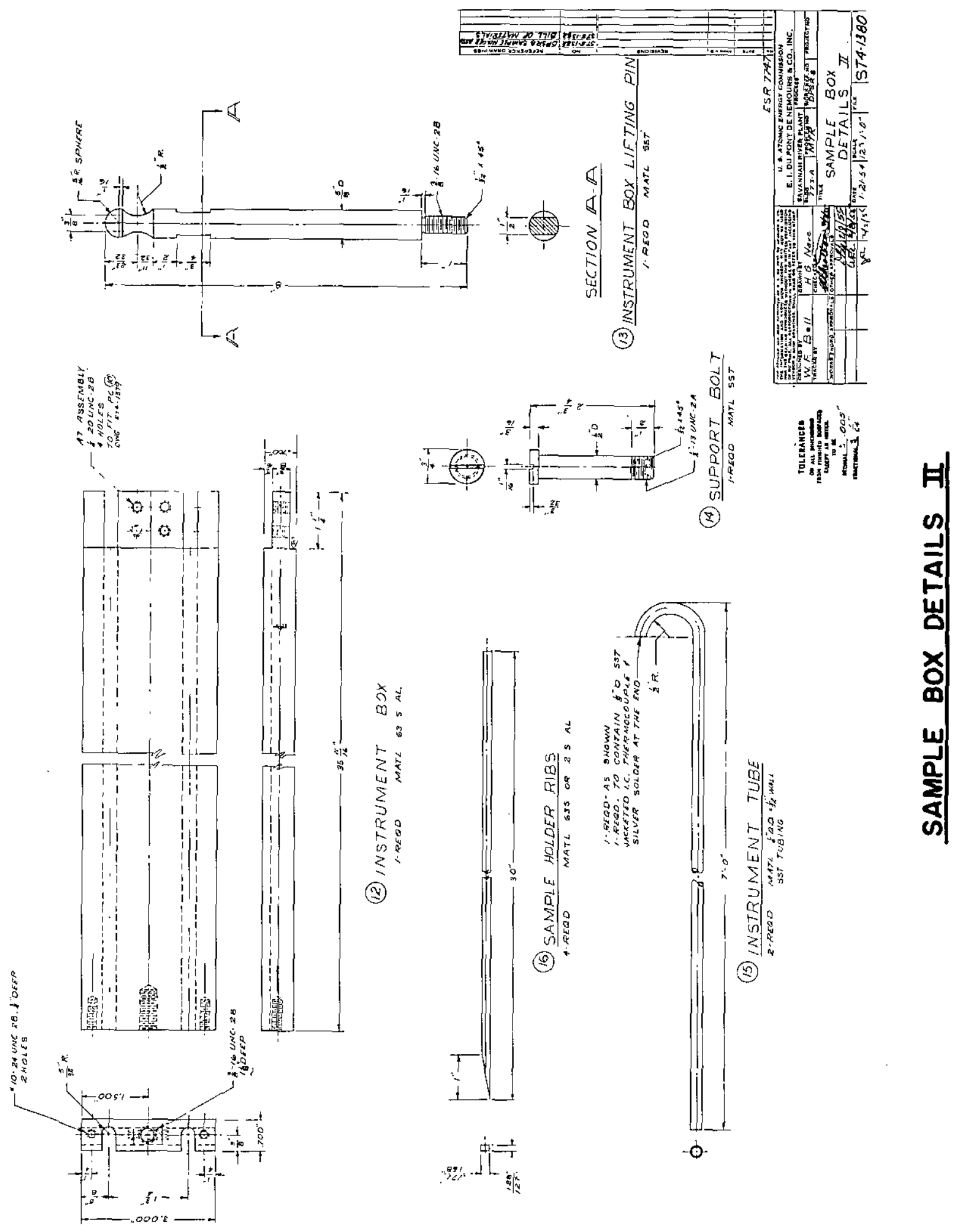

